Florida International University FIU Digital Commons

3-22-2012

\title{
Relative Importance of False Positives in the Selection Process
}

Julio E. Fernandez de Cueto

Florida International University, julfern@hotmail.com

DOI: $10.25148 /$ etd.FI12041905

Follow this and additional works at: https://digitalcommons.fiu.edu/etd

\section{Recommended Citation}

Fernandez de Cueto, Julio E., "Relative Importance of False Positives in the Selection Process" (2012). FIU Electronic Theses and Dissertations. 569.

https://digitalcommons.fiu.edu/etd/569 


\section{FLORIDA INTERNATIONAL UNVERSITY}

Miami, Florida

\section{RELATIVE IMPORTANCE OF FALSE POSITIVES IN THE SELECTION PROCESS}

A dissertation submitted in partial fulfillment of the requirements for the degree of DOCTOR OF PHILOSOPHY in PSYCHOLOGY

by

Julio Fernández de Cueto 


\section{To: Dean Kenneth Furton}

College of arts and Sciences

This dissertation, written by Julio Fernandez de Cueto, and entitled Relative Importance of False Positives in the Selection Process, having been approved in respect to style and intellectual content, is referred to you for judgment.

We have read this dissertation and recommend that it be approved.

Jesse Michel

Karl Kroeck

William Kurtines

$\overline{\text { Chockalingam Viswesvaran, Major Professor }}$

Date of Defense: March 22, 2012

The Dissertation of Julio Fernandez de Cueto is approved.

$\begin{array}{r}\text { Dean Kenneth G. Furton } \\ \text { College of Arts and Sciences } \\ \hline \begin{array}{r}\text { Dean Lakshmi N. Reddi } \\ \text { University Graduate School }\end{array}\end{array}$

Florida International University, 2012 


\section{DEDICATION}

I dedicate this work to my wife Priscilla, and two incredible daughters, Isabella and Catalina. Their continuous and unconditional love is an endless source of strength

for me. I also dedicate this to my parents who have never stopped teaching me, and my friends who unknowingly yet constantly shape my life. Without any of you, none of this would have been possible. 


\section{ACKNOWLEDGMENTS}

I wish to thank all my professors, colleagues, and classmates. In particular, I want to thank the members of my committee for their support and guidance. Their direction and input was instrumental and greatly appreciated. Specifically, I would like to thank my major professor, Dr. ChockalingamViswesvaran. From the start, he had the confidence in my abilities to succeed in the program. His patience, direction and dedication were second to none throughout this process. It has been an honor to work with such a mentor. 


\title{
ABSTRACT OF THE THESIS \\ RELATIVE IMPORTANCE OF FALSE POSITIVES \\ IN THE SELECTION PROCESS
}

\author{
by \\ Julio Fernandez de Cueto \\ Florida International University, 2012 \\ Miami, Florida

\section{Professor Chockalingam Viswesvaran, Major Professor}

This study investigated the role of contextual factors in personnel selection. Specifically, I explored if specific job factors such as the wage, training, available applicant pool and security concerns around a job, influenced personnel decisions. Additionally, I explored if the individual differences of decision makers played a role in how the previously mentioned job factors affected their decisions. A policy-capturing methodology was employed to determine the weight participants place on the job factors when selecting candidates for different jobs. Regression and correlational analyses were computed with the beta weights obtained from individual regression analyses. The results obtained from the two samples (student and general population) revealed that specific job characteristics did indeed influence personnel decisions. Participants were more concerned with making mistakes and thus less likely to accept candidates when selecting candidates for jobs having high salary and/or high training requirements. 


\section{TABLE OF CONTENTS}

CHAPTER

PAGE

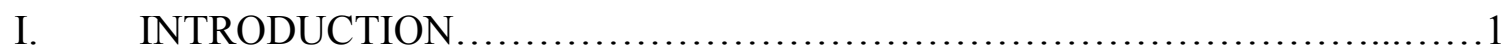

II. LITERATURE REVIEW ...................................................... 10

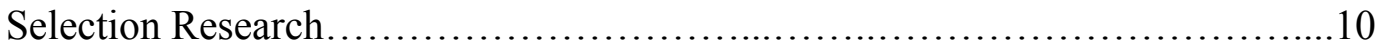

Performance Prediction Research.............................................10

Decision Making Research...............................................13

Decision Making in Organizations...................................... 16

Decision Making Models..................................................20

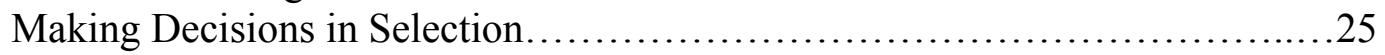

Contextual Factors in Decision Making......................................27

Individual Differences in the Decision Making Process...........................33

III. METHODOLOGY........................................................ 48

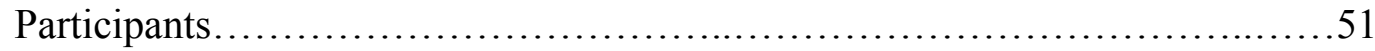

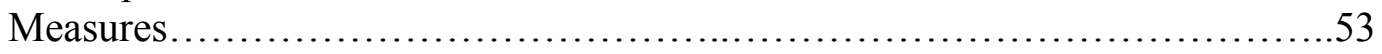

Procedure and Data Analysis.............................................58

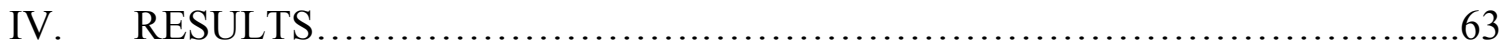

Importance Placed on Job Characteristics...................................66

Tests of Hypothesized Relationships.........................................71

Exploratory Analysis...................................................... 73

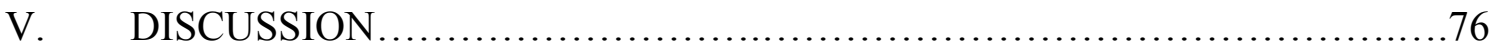

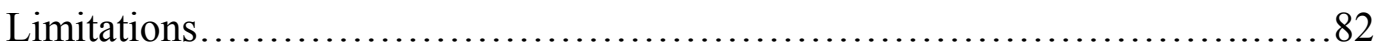

Implications for Organizations......................................... 84

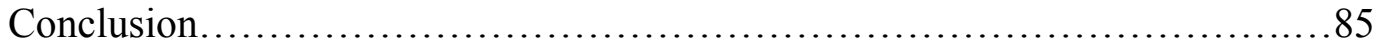

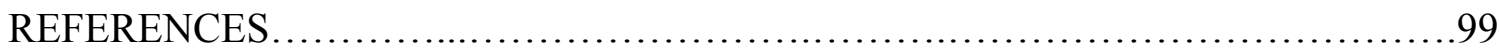

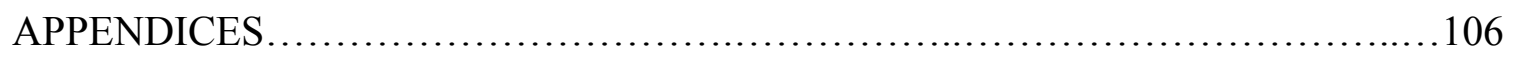

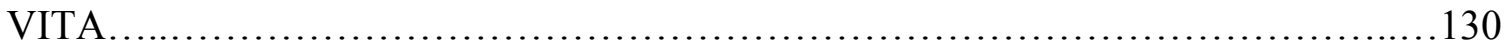




\section{LIST OF TABLES}

TABLE

PAGE

1. T-test Comparisons for Both Samples for all Relevant Independent and Demographic Variables

2. Multiple Regression Analysis of the Relationship between Job Characteristics and Decision Average across All Job Profiles for Student Sample.

3. Multiple Regression Analysis of the Relationship between Job Characteristics and Decision Average across All Job Profiles for SR Sample

4. Mean Standardized Regression Coefficients by Job Characteristic for Student Sample....

5. Mean Standardized Regression Coefficients by Job Characteristic for SR Sample .89

6. Number of Significant $\beta$ s for Student Sample..................................... 90

7. Number of Significant $\beta$ s for SR Sample.......................................... 90

8. Meta-Analysis of the Standardized beta Coefficients for Each Job Characteristic....................91

9. 95\% CI for job characteristics around standardized betas using SE for Student Sample..........92

10. $95 \%$ CI for job characteristics around standardized betas using SE for SR Sample...............92

11. Means, Standard Deviations, and Intercorrelations for Student Sample ....................93

12. Means, Standard Deviations, and Intercorrelations for SR Sample ........................94

13. Multiple Regression Analysis of the Relationship between Individual Differences and $\mathrm{R}^{2}$ for Student Sample ........................................................................95

14. Multiple Regression Analysis of the Relationship between Individual Differences and $\mathrm{R}^{2}$ for

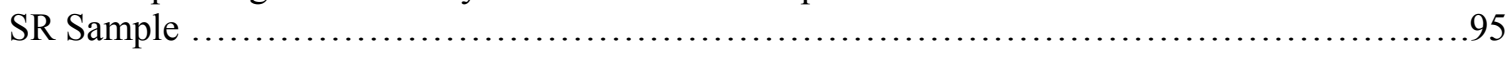

15. Multiple Regression Analysis of the Relationship between Individual Differences and Decision Average for Student Sample

16. Multiple Regression Analysis of the Relationship between Individual Differences and Decision Average for SR Sample

17. Multiple Regression Analysis of the Relationship between Individual Differences and beta weights of the job characteristics for Student Sample

18. Multiple Regression Analysis of the Relationship between Individual Differences and beta weights of the job characteristics for SR Sample 


\section{Chapter 1}

\section{Introduction}

Hypercompetition can be described as a business environment having rapid changes in which competitive advantages cannot be sustained. Today, organizational leaders face continued globalization, technological changes, and hypercompetition, complicating their ability to anticipate, recognize and avoid organizational decline (Lahiri, Perez-Nordtvedt \& Renn, 2008). Because of this, organizations are constantly looking for ways to stay ahead in their competitive business landscape. One such competitive advantage is in the organization's most valuable asset: its people (people are difficult to replace). If organizations are to remain competitive, they must effectively manage their human capital. Having the right people and skills to face the challenges begins with the process of selecting the right people. In other words, making accurate selection decisions is a critical component of an organization's success.

While selecting highly productive employees is not an easy endeavor, the results of making good selection decisions are considerable. Some researchers estimate organizations can generate large gains in productivity by selecting better employees (Hunter, Schmidt \& Judiesch, 1990). For instance, studies estimate superior workers (one ranked in $84^{\text {th }}$ percentile or higher) to produce $40 \%$ more than average workers (Schmidt and Hunter, 1983; 1998). Having above average workers means a good employee $\left(84^{\text {th }}\right.$ percentile) making $\$ 40,000$ a year will produce $\$ 16,000$ dollars more than an average employee (an employee ranked in the $50^{\text {th }}$ percentile). The difference is even more dramatic between a superior employee $\left(84^{\text {th }}\right.$ percentile and above $)$ and a poor performer (workers at the $16^{\text {th }}$ percentile). In this case, a superior worker making 
$\$ 40,000$ annually produces $\$ 32,000$ more annually when compared to a poor employee (Schmidt and Hunter, 1983; 1998).

Although the use and accuracy of these estimates can be controversial (see Cabrera \& Raju, 2001; Cascio, 1998; Hazer \& Highhouse, 1997; Latham \& Whyte 1994; Macan \& Foster, 2004 for a further explanation of these estimates), these numbers suggest that selecting and having good employees has a great impact on an organization's productivity. Moreover, better employees affect organizations in other indirect ways. For example, incompetent, unskilled or uninterested employees require more supervision and training and thus more resources. Effective selection processes also helps reduce organizational turnover. Barrick and Zimmerman (2005) found measurable factors such as pre-hire dispositions, attitudes, and behavioral intentions predicted voluntary, organizationally avoidable turnover. High turnover is very costly when considering factors such as replacement costs, training and lost productivity. Therefore hiring the right person has enormous practical implications for organizations.

Organizational leaders recognize the importance of selection as they routinely report spending more money on selection than any other aspect of human resource management (Schmitt and Chan, 1998). In its broadest sense, personnel selection involves a series of choices made by decision makers. These include which recruiting practices to implement, extent of job analysis needed, and the use of specific selection measures, among others. In a narrower sense, personnel selection is the decision used to hire or promote candidates. It involves the placing of individuals into jobs, deciding which candidates to accept and which ones to reject. The quality of a decision is the proportion of correct choices among the applicants (Born \& Scholarios, 2005). Thus, the 
ultimate goal of personnel selection is to maximize correct choices and minimize mistakes made during the selection process. In more applied terms, good selection decisions help ensure that the productivity of newly selected individuals outweighs the cost of recruiting, selecting, training, and compensating them.

Most research in selection has focused on prediction and not decision making. Research focusing on evaluating selection methods fills the selection literature, determining what predictors and selection measures work well across jobs and organizations. Unquestionably, this body of knowledge has been invaluable to organizations in selecting employees more effectively, efficiently and fairly. While research focusing on methods provides helpful insights regarding future job performance, there is a dearth of research focusing on the narrower aspect of the selection process. In fact, researchers know little regarding how people in organizations make personnel decisions. If the purpose of using selection tools is to minimize mistakes made during selection, it is important to understand the factors influencing decisions and possible selection mistakes.

Whereas the literature has been primarily concerned with predictions, making selection decisions involves choosing among several options. In making decisions, people often deal with contextual factors within their organizational environment. Moreover, as decision makers, people inject their own biases, perceptions and preferences into their decisions. In order to minimize subjective personnel decisions, researchers need to uncover the external and internal factors influencing personnel decisions. The study described herein focuses on personnel selection, filling the void in the literature by exploring the factors influencing personnel selection decisions. The 
study also contributes to the selection literature by focusing on the individual differences of the decision makers themselves. Focusing on these individual differences will lead to a greater understanding of decision-making, not simply performance prediction.

\section{Contextual factors influencing decisions}

Although previous research has provided (and continues to provide) practical insights, this dissertation goes beyond the conventional selection research by focusing on factors affecting the decision-making process. The majority of research seems to perceive decision making as an isolated process, often ignoring how external factors could affect decisions. It seems unlikely that decision makers use a systematic step-by step process to make choices guided by a set of rules and constraints without much regard to the context. After all, jobs can vary greatly across many factors such as complexity, salary, duties, etc. Would individuals use the same decision rules to evaluate a candidate and reach a similar conclusion to hire regardless of job complexity and training requirements? Would a higher paying job influence someone to be more cautious when making personnel decisions?

The environmental context in which someone makes decisions can certainly affect choices. Although the quality of a decision (percentage of correct choices) is very important, other factors may limit the value of a highly predictive selection instrument. Individuals sometimes need to make decisions under specific or constrained circumstances. For example, the labor market in which individuals make personnel decisions, could affect their selection choices. If someone is choosing among too many unqualified candidates for a large number of vacancies, they may use a different approach than someone selecting candidates under more optimal conditions. In this case, 
a decision maker may be more inclusive and thus accept candidates who may turn out to be a poor choice in order to fill a needed position. On the other hand, a decision maker with too many qualified candidates and too few positions may be less inclusive. In this instance, a decision maker may easily dismiss potential candidates. As illustrated by these examples, contextual factors are important and we need to understand their impact.

While the environmental context can influence decision makers, other internal factors can affect decisions as well. Individuals' decision-making may be affected by their own motivational and cognitive factors (Born \& Scholarios, 2003). Traditionally, the research in selection has focused on the role individual differences play from a candidate perspective. In other words, research in personnel selection has tried to find the individual differences of candidates that predict job performance. In contrast, this study explores how the individual differences of decision makers can affect decisions made during the selection process. First, it explores if contextual factors affect people differently. Secondly, it explores whether individual differences affect willingness to make riskier decisions.

\section{Individual Differences and the Effects of Contextual Factors}

In making decisions, the task is to make the best decision or judgment possible based on the information available. Individuals in some way aggregate the information available and make what they consider the best decision. Thus, individual differences can play a role in how decision makers perceive and process contextual factors in making decisions. More specifically, it seems likely that people's capacity for storing, organizing, processing and aggregating information may affect their final decisions. For example, higher levels of mental ability may lead to a greater understanding and more 
sensitivity of contextual factors. Additionally, higher levels of mental ability in decision makers may lead to greater flexibility when making selection decisions amid contextual factors. As a result, decision makers with higher levels of mental ability might perceive and understand contextual factors better, making them more susceptible to their influence.

Personality characteristics can also play a role in determining how contextual factors affect decisions. For instance, highly conscientious individuals are characterized as having a more systematic and calculating approach to work (Sears and Rowe, 2003). Therefore, conscientious individuals are likely to be more detail oriented and thus pay more attention to the contextual factors surrounding a decision. Similarly, high levels of openness to experience are often associated with being creative, novel, reflective, perceptive and thoughtful. Moreover, openness to experience has an appreciable correlation with intelligence (Judge and Bono, 2000). Thus, contextual factors are more likely to influence individuals with high levels of openness since they will be more aware and able to perceive them. In summary, individual differences may affect a decision maker's ability to understand, consider and make use of contextual factors when making decisions.

\section{Individual Differences, Risk taking and Decision Making}

Individual differences may also affect a person's willingness to take risk, which in turn may affect choices. Prospect Theory has addressed how people facing risk make their choices. The theory suggests that the way in which people frame a problem guides their decisions (Kahneman and Tversky, 1979). When placed in risky decision-making scenarios, individuals contemplating a gain become risk averse. On the other hand, when 
contemplating a loss, individuals become risk seeking. For example, a store offers people a $\$ 10$ gift certificate or a $50 \%$ chance to win a $\$ 20$ gift certificate. According to Prospect Theory, these individuals are contemplating a gain and tend to choose the $\$ 10$ certificate (avoid risk). Conversely, if someone loses a $\$ 10$ bet and is given the opportunity to pay the $\$ 10$ or make another bet as "double or nothing" proposition, would become risk seeking. In this case, individuals would be facing a loss and would more willing to take risk, and choose the "double or nothing" proposition (take risk). Essentially, how people frame problems and situations guides their choices.

However, when making decisions and framing possible outcomes, people process information through cognitive and affective filters. Risk taking may be more than just the result framing problems. Kowert and Hermann (1997), point out that about one third of subjects in experimental research do not conform to the predicted framing effect (Kowert and Hermann, 2001). That is, these individuals did not take or avoid risk as expected by prospect theory, suggesting that decisions are more than just problem framing. Contrary to prospect theory, risk propensity may be a function of the individual more than the context or given situation. Perhaps the individual characteristics of people shape their level of risk taking and decision-making. Some individuals may just be risk takers while others simply avoid it at all cost. In other words, risk taking may be a matter of awareness and stable personal preferences without much regard to context.

For example, personality may play a role in people's willingness to engage in risk taking behavior. Consistently taking risk requires security and resiliency. Therefore, emotionally stable individuals may be more likely to engage in riskier behaviors and make riskier decisions. Similarly, being open to experience (openness) would require 
being comfortable with ambiguity or uncertainty. Being comfortable with uncertainty should influence someone's willingness to take risk. Awareness may also play a role in someone's willingness to take risks when making decisions. People may inadvertently take risks if they are unaware of a risk involved. Consequently, individuals with lower levels of mental ability may not be aware of risks and thus make riskier decisions. In summary, individual differences may affect a decision maker's inherent ability to understand, seek or avoid risk. This in turn can affect choices regardless of any contextual factors or problem framing.

The goal of this research is thus to enhance the understanding of decision making during the selection process. More specifically, through a policy capturing design, this research examines if contextual factors influence selection decisions. Additionally, the research will attempt to untangle the effects of individual differences on personnel decisions. First, I examine if contextual factors affect individuals differently when making selection decisions. Secondly, I explore if individual differences lead to riskier decision making in personnel selection.

This dissertation continues in chapter 2 with a literature review. First, I review the previous research in personnel selection. After that, I discuss the framework for the decision making process guiding this research study. Then, I define a group of contextual factors and make a case for their impact on decision-making. Finally, the individual differences of decision makers are explored along with the impact these variables may have on decision making in personnel selection. 


\section{Chapter 2}

\section{Literature Review}

\section{Selection Research}

The advancements in selection theory and attention paid to selection for almost a century testifies to its importance to researchers. Countless studies and volumes have been dedicated to the practice of selection, contributing greatly to a better understanding of human resource management (refer to Ployhart, Schneider and Schmitt, 2006; Schmitt \& Chan, 1998 for a summary of the research literature in personnel selection). Schmitt and Chan (1998) outline the paradigm guiding most selection research. First, job analysis takes place to identify the tasks and responsibilities needed for a given job. Then, the KSAOs (knowledge, skills, abilities and other characteristics) needed of the individuals who will perform the tasks of the job are developed. Once the needed KSAOs are established, measures of performance and predictor variables are developed to evaluate the ability-performance relationships assumed during the initial job analysis. If the assumptions are correct, the implementation of selection procedures based on these findings takes place to determine their practical cost and benefits. Following this paradigm, research in selection has assumed candidates bring individual differences to jobs, and has sought to establish a link between these differences and a criterion indicative of performance. Accordingly, selection research has mostly focused on performance prediction.

Performance prediction research. Through the years, selection research has tried to identify the most important individual characteristics of applicants. The goal has been to uncover the underlying differences between good and mediocre candidates in 
order to select the best candidates available. Researchers wanting to discriminate between good and mediocre candidates, measured individual characteristics (i.e., resiliency, intelligence) perceived to predict performance and correlated these scores to a performance indicator (i.e., supervisory ratings). A statistically significant correlation between these two measures provides evidence of an instrument's ability to predict performance. This ability, called predictive validity, directly relates to the practical utility of a selection tool. The higher the predictive validity of a selection tool, the greater the gains are in employee performance if the tool is used (Hunter, Schmidt, \& Judiesch, 1990). Likewise, the higher the predictive validity of a selection tool is, the greater its ability to guide making good selection decisions while avoiding potentially bad ones. Because of this, the most important property of a selection instrument is its ability to predict future on the job performance and job-related learning (Schmidt \& Hunter, 1998)

Relying heavily on techniques such as meta-analysis, researchers have significantly added to our understanding of the predictive ability for different selection methods and individual difference variables (Anderson, Born \& Cunningham-Snell, 2001). After almost 100 years of research, the validity of many selection instruments and measures is well established. Researchers have used many predictors in their attempt to improve personnel selection. Among the predictors used in the selection literature are personality, GMA or general mental ability, integrity tests, employment interviews, job knowledge tests, assessment centers and graphology. Comparative evaluations of these many predictors of job performance are available in the selection literature (Hunter \& Hunter, 1984; Salgado, Viswesvaran \& Ones, 2001; Schmidt \& Hunter, 1998). The 
performance prediction research is useful, practical and necessary. It is instrumental in helping decision makers better predict performance across many jobs and thus make better personnel decisions. Moreover, this research, which contributes to a better understanding of the relationships between job tasks and required skills and abilities, provides valuable knowledge for other human resource areas such as training and development, recruitment, performance appraisal, and compensation.

Because of its usefulness and practical impact to organizations, most of the research in selection has focused on performance prediction. It has not however, been the only focus of selection research. Researchers have also explored other aspects of the selection process. For instance, some researchers have focused on selection from a candidate's perspective. These studies explored candidates' reactions and decision making during selection (see Anderson and Witvliet, 2008; Anderson, Born \& Cunningham-Snell, 2001; Hausknecht, Day \& Thomas, 2004 for a thorough review of this research topic). Knowing candidate reactions has helped organizations understand how their selection efforts (i.e., selection tools and methods used) affect applicants' decisions to apply and their reactions to selection processes. Applicants' reactions can in turn affect an organization's reputation, legal involvement and ability to recruit desirable candidates. This stream of research helps exemplify the complexity of personnel selection. Selection involves more than statistical predictions regarding candidate suitability for a job (Anderson, Born \& Cunningham-Snell, 2001). At the very least, selection involves several players, making multiple decisions while influenced and motivated by a number of internal/external factors. Recognizing this notion, some 
researchers have explored personnel selection as a decision-making process and not just predictive testing. I now review this research.

Decision making research. Policy-capturing studies have examined decision making in personnel selection. In particular, researchers have explored which predictors managers focus on when assessing possible candidates (Dunn, Mount, Barrick \& Ones, 1995; Ones \& Viswesvaran, 1999). Dunn et al. (1995) examined the relative importance managers placed on applicant attributes when assessing their suitability for employment. Dunn et al. (1995) analyzed the manner in which managers used information about applicant personality and general mental ability in determining their qualifications. In other words, they studied what candidate attributes the managers focused on when making selection decisions.

Results showed that managers found general mental ability and conscientiousness as the most important attributes related to hirability (composed of perceived qualification, and expected performance). That is, managers placed the most importance in these two attributes when reviewing candidates and making judgments regarding their hirability. These findings were consistent with the existing empirical literature and meta-analytic reviews of validity studies (Dunn et al., 1995). Reviews of the validity studies have established intelligence (GMA) and personality (conscientiousness) as the most parsimonious combination of predictors for job performance across many jobs. Therefore, managers used characteristics deemed relevant in the personnel selection literature as their greatest cues when rating the hirability of candidates (i.e., GMA and conscientiousness). 
However, Dunn et al., (1995) also asked participants to rank order the importance of attributes (GMA and Big Five) in making hiring decisions. The researchers then rank ordered the standardized regression weights (by size) of the six cues used in their study (Big Five and GMA). Spearman rank-order correlations coefficients were computed between the ranked beta weights and the rankings assigned by the participants. The rank-order correlations calculated across all participants showed only moderate levels of agreement. Correlations between ratings (standardized regression weights) and rankings were .60 and .33 for hirability and counter-productivity, respectively. In other words, how raters felt they made decisions was not how they actually made them.

Moy \& Lam (2004) conducted a similar study in Hong Kong and somewhat replicated these results. First, like the policy capturing study by Dunn et al. (1995), conscientiousness of applicants was a very important criteria for hirability. Unlike previous findings, results in this study did not show general mental ability as an important characteristic for hirability. This finding, which is in contrast to Dunn et al. (1995), might have been because of the manner in which the researchers operationalized mental ability. The researchers used academic performance as an approximation to intelligence as opposed to the descriptors used in Dunn et al. (1995) which included words like dull and bright.

Similar to previous findings, Moy \& Lam (2004) report decision-makers only have a moderate degree of understanding regarding their own decisions. Results showed discrepancies between what recruiters said was important in making decisions and the way in which they actually weighed them in their assessment of the candidates (Moy \& Lam, 2004). In the self-reported results, agreeableness ranked as the second most 
important attribute used in making judgments. In analysis however, agreeableness had the lowest relative importance. These findings along with those of Dunn et al. (1995) are significant because they suggest there are other factors beyond methods used during selection affecting decisions made. Moreover, decision makers may not be completely aware of how they are making decisions.

Other research in the selection literature exploring how people make decisions includes the ASA model and the "similar to me" effect. The attraction-selection-attrition (ASA) framework proposed by Schneider $(1987 ; 1995)$ suggests that the outcome of three interrelated dynamic processes, attraction-selection-attrition, determines the kinds of people in an organization, which in turn defines the organization's structures, processes, and culture (Schneider, 1995). Organizations attract certain people to apply and select those who share their values. Those who do not fit, simply leave the organization over time. In the ASA model, people select candidates that are similar to them. Likewise, in what is called the "similar-to- me" effect, research has shown that interviewers inflate ratings of candidates who posses similar demographic and attitudinal characteristics to themselves (Sears \& Rowe, 2003). In selection, it would be an inclination of decision makers to select candidates similar to them in regards to some individual characteristic such as demographics and background. In their study, Manshor, Jusoh and Simun (2003) examined the effect of hiring managers' demographic characteristics on employee selection preferences. Results indicated the effect of managers' demographic characteristics to be significant for both race and religion. Managers had preferences to hire those of the same race and religion as theirs. 
Moreover, this preference remained high even if the candidates similar to the decision maker had lower qualifications (Manshor, Jusoh \& Simun 2003).

Several explanations have emerged for these biases in decision-making. For instance, Frank \& Hackman (1975) propose that similarity increases the chance that the rater's opinions and views are validated. Validating one's opinion in turn leads to positive feelings emerging towards the other person being rated. Frank \& Hackman (1975) also propose that low self-esteem and experience moderate this relationship. That is, individuals with low self-esteem and little experience would be more receptive to selfvalidation and thus to the similarity bias. Leonard (1976) found that cognitive complex individuals were more likely to perceive similarities in applicants and evaluate them more favorably. Regardless of the reason, it is apparent that decision makers bring their individual differences to the table when making decisions. Thus, the question of which individual differences might affect decisions becomes important in the selection literature. Moreover, it is important to consider what other factors beyond the decision maker can also impact personnel decisions. As mentioned before, selection decisions do not take place in isolation. Rather, they take place within the context of an organization embedded in the larger society.

Decision making in organizations. Some studies have recently focused on the organizations, exploring the reasons behind their selection practices. Given how much of the selection research has focused on performance prediction, it seems organizations should be well positioned to leverage this knowledge. Organizations would simply have to use the best predictors of performance and select the best candidates using these tools. There is however, a large gap between what some researchers call the science and 
practice in personnel selection. In spite of all the research available regarding selection methods, organizations often adopt unstandardized, unreliable, invalidated and biased selection methods, when there are much better and well-established alternatives (Klehe, 2004). Evidence-based management (EBM) has emerged as an initiative to promote the use of the best scientific evidence to inform professional practice. Evidence-based management aims to integrate the practitioner's expertise with the evidence of research (Briner \&Denise 2011). It is about obtaining and using the best available evidence to make the best decisions possible. In other words, EBM helps bridge the gap between scientific evidence and practice.

Researchers typically explain this gap alluding to a lack of knowledge transfer, failure of utility information to convince decision makers and economic or time pressure (Klehe, 2004). For example, some feel the research fails to explain results in practical terms and findings remain hidden in technical jargon (Rynes, Colbert, \& Brown, 2002). Others feel research rarely takes into account many contextual factors (e.g., budget, time constraints), leaving practitioners to fit what tools and methods to employ (Ryan \& Tippins, 2004). Klehe (2004) believes these are simple explanations to a complex problem, and do not take into account the complexity of the diverse pressures organizations face regarding selection procedures. The basic issue remains, that is to understand why or how organizations choose their selection strategy and what influences their decisions.

Klehe (2004) proposed that an organization's objective of achieving economic and social fitness influences their choice of selection procedures. Economic fitness involves long-term economic considerations (gains from having valid selection 
procedures) and short term economic fitness (having cost-efficient solutions to fill urgently needed positions, thus avoiding loss in production). Social fitness involves the legal ramifications organizations may face in choosing a selection strategy and the candidates' reaction to such strategy (Klehe, 2004). At times, these two social factors may even work at odds with each other. For instance, legal concerns may influence an organization's choice to go with well-developed selection procedures (i.e. structured interview). On the other hand, applicants may sometimes react more favorably to less refined measures such as unstructured interviews since these provide them more control to influence the outcome. These suggestions imply that many factors can affect an organization's decisions in personnel selection. Moreover, these factors are unrelated to individual differences among the candidates and yet affect the selection process and any decisions that come from it.

Wilk and Cappelli (2003) also examined the selection process from the organization's perspective. The authors analyzed employers' selection decisions by focusing on the impact the work characteristics had on selection practices. Organizations cannot use too many selection methods at once for it would be too time consuming and costly. Instead, they must choose the selection method that provides the most useful information. Wilk and Capelli (2003) sought to understand how organizations match their need to a selection method. The authors hypothesized that differences in the nature of work affected the use of specific types of selection methods.

Results showed that skill requirements, training required and wage were all predictors of the extent to which organizations used selection methods (positively related). Organizations were more likely to employ selection methods for more 
demanding and higher paying work. Additionally, Wilk and Cappelli (2003) found that the selection methods employed varied by work characteristics. For instance, training requirement (hours of formal training provided) had a stronger relation to the use of ability and skill related selection practices (i.e. achievement and performance tests) than to work experience methods. In higher paying jobs, organizations were more likely to base their decisions using work experience and not academic achievement. These findings suggest that organizations base their selection methods on the work needed. In effect, these work characteristics influence how firms select employees (Wilk and Capelli, 2003). Likewise, work characteristics can affect decision makers when implementing these practices.

In summary, decision-making in personnel selection seems to be viewed often as a rational process where people make consistent decisions among rational choices. Researchers have primarily focused on how selection methods can help organizations make accurate predictions of job performance and help select the "best" candidate for a position. The assumption is that decision makers select the best candidate from a topdown list of qualified candidates. However, it is evident other factors are influencing decisions in selection. Previous research has taught us that decision makers have limited insight into their own decision making process (Dunn et al., 1995; Moy \& Lam, 2004), have limited information or are misinformed regarding selection tools (Ryan \& Tippins, 2004; Rynes, Brown \& Colbert, 2002; Rynes, Colbert \& Brown, 2002), and make decisions based on factors other than assessment-performance linkages (Frank \& Hackman, 1975; Klehe, 2004; Manshor et al., 2003). As demonstrated by these findings, it is clear there are many stakeholders, factors, and issues affecting selection decisions. 
Undoubtedly, how people make selection decisions needs to be better understood. Schmitt and Chan (1998) suggest it is not enough to focus on selection methods and assess the relationship between predictors and performance. Instead, the decision making process should be better understood. I will now explore the decision-making process in selection.

\section{Decision Making Models}

Carson and Connerley (2003) and Born and Scholarios (2005) have proposed models focusing on the decision making process in personnel selection. These models recognize the complexities surrounding staffing decisions and provide integrated frameworks to better understand how staffing occurs in organizations. Unlike traditional research focusing on prediction, this research focuses on trying to understand how individuals and organizations actually make selection decisions. The researchers argue that understanding the way in which people make decisions in selection should be the focus in the literature. To this end, the proposed models identify decision-making in selection as a multi-level process influenced by many stakeholders and contextual factors that help determine selection in organizations.

Carlson and Connerley (2003) put forth the first model. They propose an alternate view of staffing where decisions made by individual applicants and organizations are independent events. By focusing on staffing decisions (not processes or activities), Carlson and Connerley (2003) believe there is greater conceptual clarity and simplicity. This in turn, can help articulate what factors and influencing mechanisms impact selection outcomes and decisions made (Carlson \& Connerley, 2003). To this end, Carlson and Connerley (2003) developed The Staffing Cycles Framework (SCF). 
The researchers wanted to gain a greater understanding of the staffing process. The SCF is a group of interrelated decision events articulating how staffing takes place. These events extend from an individual deciding to enter the workforce, an organization establishing an opening, an individual applying, organization making an offer, individual accepting the offer and so forth. These decision events become the building blocks of staffing. Essentially, each decision involves a decision maker who engages in problem solving and decision making activities in order to affect a choice or decision (Carlson \& Connerley, 2003).

The SCF views staffing as a dynamic mixture of actors, context and actions that frame how and when staffing outcomes are affected. It describes the interrelationships among the actors, contexts, and activities during decision events to understand their influence. Actors are those individuals having a capacity to act and make decisions (i.e. individual applying and the organizational decision maker). These actors often act as decision makers and alternate the responsibility for determining how to solve a problem at each decision event. Additionally, because SCF is an open system, others beyond the primary actors can influence decisions. These actors, referred to as third party influencers, include the government, unions, friends, consultants, family and customers (Carlson and Connerley, 2003).

In the SCF framework, actors make decisions within a context. Context refers to factors present in the environment at the time in which actors are making decisions and can influence outcomes. The primary context variables are decision characteristics and decision environment. Decision characteristics can include the complexity of the environment, timeframe to make a decision and any special requirements (i.e., using a 
legal process). The decision environment can be any factor other than the actions of actors that could influence decisions during an event. These include data about a candidate, data about the position, codified rules, procedures, and the resources available (Carlson and Connerley, 2003). Finally, the SCF involves actions which are all activities taken by actors during decision events.

The Staffing Cycles Framework is an attempt to explore the connections and interdependencies among actors, context and actions in organizational staffing. It proposes a system views to staffing, which includes selection, with multiple sources of influence and interrelated activities. The SCF therefore recognizes that actors (applicants and organizational decision maker) and the environment can influence decisions during personnel selection. Identifying these influencing factors and understanding how they affect decisions is critical to gain a better understanding of personnel selection in organizations (Carlson and Connerley, 2003).

Born and Scholarios (2005) proposed the second model of personnel decisionmaking that guides the present study. Like the previous one, the Born and Scholarios model also focuses on decision-making instead of the predicting phase of traditional selection research (which focuses on what to measure, how to measure, developing measures, etc.). The authors propose that when making selection decisions, a host of factors affect decision makers. First, decision makers' own individual motivational and cognitive factors affect their decisions (individual subjectivity). These distortions, occurring at a micro level, can often result in less than straightforward decisions, particularly as tasks become more complex and uncertain (Born \& Scholarios, 2005). A higher level of influence occurs at an organizational level. Decision makers work in the 
context of organizational characteristics which guide and possibly impose constraints on their decision making process. For example, factors such as the strategic direction of the organization, patterns of turnover, organizational size, and organizational culture can impact decisions (Born \& Scholarios, 2005)

Finally, a third and wider level of influence also affects selection decisions. This macro level is the organization's external environment. Individual make decisions while their organizations are subject to social influence that further impact decision makers (Born and Scholarios, 2005). For example, the local labor market can influence the selection strategy of an organization, which in turn affects the decision maker. If an organization attracts many good applicants, their hiring managers can afford to be more selective. In summary, Born and Scholarios describe the process of selection as containing three layers influencing decision-making: the individual decision maker, the organizational context, and the larger environment in which the organization exists (Born and Scholarios, 2005).

Establishing selection as a methodical multi-decision process having several layers of influence implies organizations and decisions makers need to be well informed and organized in order to make effective selection decisions. In its current state, the selection literature informs and effectively summarizes the methods and processes that work best in making selection decisions. Organizations no doubt benefit from this research. It helps improve accuracy of selection decisions, which in turn is important in determining the quality of a decision. As evidenced by the amount of research involving predictive validity and selection methods, the focus of the literature is on increasing the understanding (and hopefully adoption) of selection methods while creating better 
selection tools. Likewise, increasing the understanding of the decision-making process and the effect decision makers, organizations and the larger environmental context have on decision-making can lead to more effective personnel selection.

In the more recent literature, some are calling for this shift in the selection research paradigm. A shift from studies focusing on predicting performance, to studies focusing on learning more about actual decision-making. This study will follow this lead and examine how decision-making takes place in personnel selection. First, I define personnel decision-making in the context of this study. Then, drawing from the previously discussed selection models, hypotheses regarding contextual variables affecting personnel decision are presented. Finally, I explore in two ways if the individual differences of decision makers play a role in their decisions. First, do individual differences determine the level of influence contextual factors have on decisions? Second, can individual differences affect the willingness to make riskier decisions?

\section{Making Decisions in Selection}

In making personnel choices there are four possible outcomes, two positive (correct) and two negative (incorrect) choices. Positive outcomes are correct acceptances or true positives (hiring a good performer), and correct rejections or true negatives (correctly rejecting/not hiring a bad candidate).

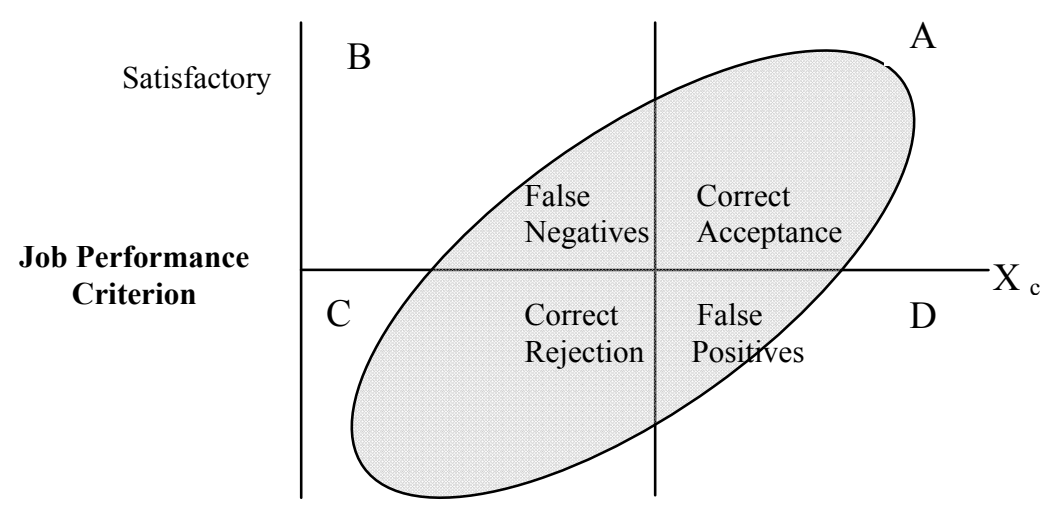


Unsatisfactory

$\begin{array}{ccc}\mathrm{X}_{n} & \text { Accent } \\ \text { Reiect } & \text { Predictor }\end{array}$

The two negative hiring outcomes are false positives and false negatives. False positives describe applicants incorrectly accepted for employment, as they were unsuccessful in their jobs. False negatives describe good applicants incorrectly rejected for employment.

Decision makers in personnel selection must avoid both errors but the relative emphasis on the two errors is an open question influenced by both individual and contextual factors. On one hand, if someone is conservative in making decisions or selection criteria is too strict, this person risks rejecting a potentially good candidate. Conversely, if someone is more relaxed and lenient in making selection decisions, false positives become a concern as the likelihood increases of selecting a "poor" candidate. In the case of incorrect decisions or mistakes, focusing on reducing one type will generally increase the other. For example, if a decision maker wants to reduce the number of false positives (block D), the predictor $(\mathrm{Xp})$ needed for acceptance into a job is increased (moved to the right). While the numbers of false positives are reduced (block D would be smaller), the number of false negatives would also increase (block B would be larger).

In many selection situations, false positives are worse than false negatives (Cascio, 1998). When organizations make false positive errors, they hire candidates to jobs that are beyond their levels of competence. Making false positives results in a suboptimal use of personnel coupled with the possibility of costly damage for the organization and the person wrongfully selected. Conversely, when organizations make 
false negative errors they fail to hire applicants for jobs they are competent to perform. False negatives result only in a possible sub-optimal use of personnel (although a better candidate was possibly hired), but ultimately unlikely to result in damage to individuals or organizations in the same way false positives might. Decision makers are thus more concerned with accepting the wrong candidates and seek to reduce false positive errors since rejected candidates (including false negatives) never make it into the organization and result in less quantifiable and apparent errors. That is, in most organizational contexts, false positives are visible but false negatives are the invisible errors (unless the false negative is employed with a competitor and is hugely successful in the profession).

Taking risk in personnel selection is thus a matter of which error to avoid.

Committing false positives errors is the greater risk for decision makers. False positives are visible in an organization whereas false negatives never make it to the organization. Selecting a poor candidate will be noticed by everyone in an organization and would reflect negatively on the person who made the decision. Risk taking, in the context of this study, is thus defined as a person's willingness (or not) to increase the likelihood of false positives. Because decision makers will tend to be more concerned with false positives, this study will focus on false positives and hypotheses will reflect decision makers' tendency to reduce this type of error. There are three types of hypotheses presented in this study. First, some hypotheses address the role of contextual factors in decision-making. Then, a second group of hypotheses test the role individual differences have on the influence of contextual factors. Finally, some hypotheses evaluate the role of individual differences on risk taking in selection. I now discuss the first part, contextual factors in personnel selection. 


\section{Contextual Factors in Decision Making}

Every decision in selection is embedded in a context defined by the features of the specific environment at the time of decision-making (Carson and Connerley, 2003). The decision making process is influenced by multiple levels of contextual factors. In this study, I examine contextual factors at two levels. First at the broadest level of influence, by examining the impact the external environment has on decision-making and then at a narrower level, by examining the effect specific job characteristics have on decisionmaking. In general, the external environment's influence on decision-making is any influence coming from outside of the organization. Examples of external influencers include applicant pool, labor market and litigation (Born and Scholarios, 2005). Carlson and Connerley (2003) also suggest laws/regulations may confine someone's choices and influence decision-making. Other research has found that culture affects the use of selection practices. Ryan, McFarland, Baron, and Page (1999) found that cultural differences partially explain differences in selection use across different countries. For instance, organizations in societies with high uncertainty avoidance (they are more rigid and conforming to norms), were found more likely to use interviews and tests in the selection process (Ryan et al., 1999).

In the present study, consistent with Born and Scholarios' (2005) suggestion, I assess the impact of labor market/applicant pool on decision-making. It seems likely that having a larger or smaller pool of applicants will influence how decision makers choose candidates. For instance, if selecting among 20 people for two positions versus selecting from three candidates for two positions, a decision maker can become more selective as there are probably more qualified candidates in the larger applicant pool. In the classical 
selection literature, selection ratio refers to the number of openings divided by the number of applicants (Cascio, 1998). If the selection ratio is very high (meaning a lot of openings and not many candidates), the utility of selection instruments is limited because organizations cannot be very selective. On the other hand, if decision makers have a large pool of applicants, and not as many openings, they can be more selective and thus more likely to leave a possible successful candidate out. In this case, decision makers are more likely to reduce false positive errors so they would be increasing the quality of their selection pool and making decisions among more qualified candidates. Hence:

H1: Decision makers will place more importance on avoiding false positive errors when selecting candidates for jobs having low selection ratios (many candidates are available) than when the selection ratios are high.

The second level of contextual factors examined is the job itself. Specifically, if job characteristics influence decision-making in selection is explored. Carlson and Connerley (2003) suggest data about a job among the factors affecting decision-making. In this study, I examine three specific job characteristics and determine if they affect the decision-making process. The first job characteristic assessed is regarding the safety concerns associated with a given job. More precisely, if decision makers make selection decisions differently for jobs in which people are responsible for the safety of others. For instance, a job associated with the safety of others might prompt someone to be more inclined towards making more false negatives as the cost of having false positives might be too great. Organizations are wary of litigation and legal ramifications of their 
decisions. Having made a poor choice in this situation may bring unwanted attention/accountability to the organization and decision maker responsible.

A possible explanation for this suggested tendency might come from the legal ramifications of not properly following selection procedures. There is some evidence to suggest that when decision-makers feel accountable in selection, they make judgments that are more valid. In their study, Brtek \& Motowidlo (2002) found that holding people accountable for the process by which they made judgments, increased the correlation between the interviewers' assessment ratings and supervisor ratings of employee job performance. Attentiveness mediated this relationship. Therefore, when individuals were procedurally accountable for their interview decisions, they visibly paid more attention to the interview information and thus made better judgments (Brtek \& Motowildo, 2002). However, holding individuals accountable for their decisions and not the process did not have the same effect, as it did not increase the validity of assessments.

Further explaining why the safety concerns of a job might affect personnel choices is the issue of negligent hiring. Employers are responsible if they place someone in a job where they can injure others. For example, in negligent hiring, if a job requires no contact with others and presents no danger to others, a decision maker does not have as much responsibility to investigate an applicant's background beyond checking past employment or other relevant information. On the other hand, if the job duties involve frequent contact with others or contact with vulnerable individuals such as children, the decision maker has a greater responsibility to investigate the applicant's background and be more cautious. Many individuals and organizations can find themselves in lawsuits stemming from negligent hiring. Quite often, once a person is hired, the employer holds 
much of the responsibility for that employee's behavior. In summary, the responsibility to use reasonable caution in hiring will be affected by the nature of the job duties. Thus, decision makers are expected to exercise due diligence if potential new employees represent a risk to others in the context of a job.

Brtek \& Motowildo's (2002) findings coupled with concerns over negligent hiring should indeed make individuals feel accountable about following the decision making process and being very thorough when making personnel decisions for jobs involving the public's safety. If a decision maker selects what turns out to be a false positive but follows the process established (assuming it is legal and valid), utilizes appropriate selection tools and makes decisions accordingly, the organization and the decision maker are less likely to be accountable for the mistake. On the other hand, if upon scrutiny of the selection process, a false positive is the result of ignoring or improperly implementing the selection process, both the organization and the decision maker are likely to be accountable. Thus, decision makers will be far more selective and cautious when making decisions for these jobs involving the safety of others, as mistakes will prove to be costlier. In this case, decision makers will look to reduce false positive errors as this would also decrease the likelihood of being held accountable for a bad decision. Therefore:

$$
\begin{aligned}
& \text { H2: Decision makers will place more importance on avoiding false } \\
& \text { positive errors when selecting candidates for jobs having high } \\
& \text { safety concerns than for jobs with less safety concerns. }
\end{aligned}
$$

The next job characteristic explored in this study is position salary/wage. Among the most mentioned organizational factors in selection is the size and resources available 
to an organization (Terpstra \& Rozell, 1993; 1997). Research shows larger organizations are more likely to have institutionalized human resource departments and thus adopt formalized staffing processes (Born and Scholarios, 2005). Similarly, Carlson and Connerley (2003), propose that an organization's resources (i.e. time, money) are among the contextual factors that could influence decision making during a decision event. Typically, there is a high cost associated with hiring someone who performs poorly or leaves the organization prematurely. This should be even more so for higher paying jobs. When wages are high, the cost of unproductive employees is greater (Wilk \& Capelli, 2003). Additionally, when staffing for a high paying position, mistakes are more visible since these jobs will have a higher profile.

There is some evidence suggesting specific characteristics of work relate to the actual selection practices used by organizations. That is, job factors such as salary/wage can impact the types and amount of selection methods used by an organization. Wilk and Capelli (2003) reported that for jobs having higher wages, organizations used a more extensive selection process and used more sources of information to make selection decisions. Because resources are so important to an organization, it seems reasonable to expect decision makers to exercise greater caution when staffing for jobs involving more resources. Quite often, the pay level of a job suggests how much value the work that particular job means to the company. Hence:

\section{H3: Decision makers will place more importance on avoiding false} positive errors when selecting candidates for jobs having higher wages than for jobs with lower wages. 
Like job salary, trainability of a job can influence decision-making. Jobs that are highly difficult to train or require extensive training can influence an organization to invest in selection up front to avoid training candidates from a low based skill level. Additionally, a position having high training needs implies the organization will need to make a substantial investment in the candidates selected. Wilk and Cappelli (2003) found a positive correlation between investment in training and the extent of use of selection methods. When skill requirements were greater for a position, employers had a greater need to engage in more selection activities.

Engaging in more selection activities suggests organizations and decision makers use further evaluations of candidates if a job requires a great deal of training. In other words, if the training needs are high for a particular position, decision makers are more selective for two reasons. First, hiring someone with more ability can reduce the amount of training needed (also reducing cost). Secondly, the greater the training needs are, the greater the resources the organization needs to make on the candidate. Thus, mistakes are more costly and will surely have greater visibility. It seems reasonable that organizations and decision makers would exercise greater caution when staffing for positions requiring a significant amount of training. Therefore:

H4: Decision makers will place more importance on avoiding false positive errors when selecting candidates for jobs having higher training requirements than for jobs with lower training requirements. 


\section{Individual Differences in the Decision Making Process}

The next level of influence on decision makers is decision makers themselves. More specifically, I examine the individual differences that influence decision makers'

judgments. Several studies have demonstrated how cognitive and affective processes can impact decisions. For instance the impact of first impressions (Dipboye, 1982), stereotypes (Arvey, 1979), and similarity effects (Rand \& Wexley, 1975) on ratings has been well documented. The "similar to me effect" is an area of research in which the influence of the interviewer's (or decision maker's) individual characteristics is systematically examined. Overall, "similar to me" findings suggest that the more similar an interviewer or a rater and a candidate are, the more favorably the candidate will be assessed.

There is evidence to suggest that individual differences moderate the similar-tome effect. Frank and Hackman (1975) analyzed the ratings of three college admissions officers to determine if the effect of interviewer-interviewee similarity was consistent across all three raters. The researchers found the relationship between interviewerinterviewee similarity and favorableness varied from non-existent for one officer, low positive for another, to strong positive for the third officer. Similarities between interviewer and candidate found to demonstrate this "similar to me" effect have included biographical (Rand \& Wexley, 1975), racial (Lin, Dobbins, \& Fahr, 1992) and personality variables (Sears \& Rowe, 2003). These findings suggest that individual differences in raters affect their ratings and ultimately affect their decisions.

Like the "similar to me" effect research, this study examines if the individual differences of decision makers affects their decision-making. First, I test if the 
importance of the contextual factors previously reviewed (selection pool, safety concerns, salary, and training requirements) on avoiding false positives is influenced by individual differences. Secondly, I determine if individual differences play a role in risk taking when making decisions, regardless of contextual factors. The individual factors explored in this study are cognitive complexity and personality. An overview of these two predictors follows and hypotheses are presented for their expected influence on decision making and risk taking.

Cognitive complexity. Researchers have used cognitive ability in the personnel selection literature on a countless number of validity studies. Its utility in selection has been assessed across most jobs and has been found to have the highest validity and lowest application cost (Schmidt and Hunter, 1998). General cognitive ability research and meta-analyses of this research has repeatedly shown cognitive ability measures to be among the most valid predictors of performance (Ghiselli, 1973; Hunter and Hunter, 1984; Salgado and Anderson, 2002). Although there are numerous definitions of cognitive ability, I will make use of a few definitions in this dissertation to explore the relationship between the cognitive processes of decision makers and the decision making process.

Wechsler defined intelligence as "the aggregate or global capacity of the individual to act purposefully, to think rationally and to deal effectively with his environment" (quoted in Kaplan \& Saccuzzo, 1997). Sternberg (2000) proposes three major components of intelligence. These are componential (or analytic), experiential (or creative), and, contextual (or practical). The componential element of intelligence, composed of academic problem solving skills is the ability to analyze and evaluate ideas, 
solve problems and make decisions. Experiential intelligence involves adapting to a situation or generating novel and interesting ideas. Contextual intelligence involves the ability of people to use their experience and find the best fit between themselves and the demands of the environment to solve a problem.

An editorial published in 1997 endorsed by many experts in the field, described intelligence as "a very general mental capability that, among other things, involves the ability to reason, plan, solve problems, think abstractly, comprehend complex ideas, learn quickly and learn from experience. It is not merely book learning, a narrow academic skill, or test-taking smarts. Rather, it reflects a broader and deeper capability for comprehending our surroundings - "catching on," "making sense" of things, or "figuring out" what to do" (Gottfredson, 1997).

Researchers have also examined the effect of cognitive processes such as cognitive complexity (Wofford, 1994) on decision-making. Cognitive complexity refers to the degree in which people apply multiple perspectives when evaluating stimuli (Goodwin, 1991 as cited in Wofford, 1994). In other words, cognitive complexity represents the degree to which individuals use information to apply multiple perspectives when evaluating stimuli (Goodwin \& Ziegler, 1998). Cognitively complex individuals will evaluate situations from multiple perspectives whereas cognitively simple individuals will not. When rating, cognitively complex raters are less lenient and display less halo than cognitively simple raters (Schneier, 1977). In studying cognitive complexity and clinical judgment, Spengler \& Strohmer (1994) found counselors with high cognitive complexity to be less biased in making clinical judgments, were better 
able to avoid stereotyping and were more adept at integrating client information. Finally, Ceci \& Liker (1986) found cognitively complex individuals were better decision makers.

Current research in selection provides answers to who are the best candidates (predictive studies). However, what decision makers do with this information can be critical to making good selection decisions. Studying cognitive variables provides insight into how individuals store, organize, and process information when performing organizational tasks (Goodwin \& Ziegler, 1998). Thus, cognitive complexity provides a valid starting point to research the impact of individual differences on personnel decisions.

Using the concepts of intelligence and cognitive complexity presented here makes plausible the assumption that decision makers with higher levels of cognitive complexity might be more likely to understand, respond to, and interpret factors and cues in decisionmaking. The underlying assumption is that cognitive complex individuals process information differently and perform certain tasks better because they utilize more categories to discriminate among stimuli (Hooijberg, Hunt \& Dodge, 1997). Thus, cognitively complex individuals will distinguish better among the different cues presented. Moreover, cognitive complex individuals will seek out more information (Tuckman, 1964) and spend additional time interpreting this information (Dollinger, 1984). Therefore, decision makers with higher levels of cognitive complexity will be more aware of the cues and use them in making decisions.

H5a: Decision makers with high cognitive complexity scores will have higher cue usage when selecting candidates. 
The previous hypothesis predicts a positive relationship between higher cue usage and cognitive complexity because cognitive complexity can lead to better information processing and perception. Similarly, cognitive complexity could affect a decision makers' ability to perceive the risks involved in making selection decisions. This in turn can determine whether someone makes riskier selection decisions. In the risk taking literature, researchers often assumed that individuals who were entrepreneurs and started their own businesses were predisposed to taking risks (Busenitz, 1999) and often engaged in greater risk taking behaviors. It seems logical to think of entrepreneurs as risk takers given the large proportion of businesses that fail coupled with the financial risks involved in staring up most business ventures. Although there is an inherent risk in starting a new business, there is a lack of empirical evidence to support the theory of entrepreneurs having a greater propensity for risk taking (Busenitz, 1999).

A possible explanation for this finding is the lack of risk perception by entrepreneurs. In their research, Palich and Bagby (1995) found no significant differences between entrepreneurs and non-entrepreneurs on a risk propensity scale. In other words, entrepreneurs did not perceive themselves as being predisposed to risk taking. Instead, the researchers found that entrepreneurs categorized business scenarios more positively than their non-entrepreneurs counterparts. It seems entrepreneurs perceive their chances of succeeding to be greater and thus fail to acknowledge the risks associated with some decisions. It seems that perhaps entrepreneurs make riskier choices because they perceive little risk in their proposed ventures (Busenitz, 1999).

Similarly, a person's ability to understand and perceive risk can influence their willingness to engage in risk in personnel selection. Having higher levels of cognitive 
complexity may increase awareness of the risks associated with any decision and influence the decision. Stated differently, cognitively simple individuals may not accurately interpret, perceive and understand information due to their limited cognitive capacity. This includes an inability to perceive riskier situations. Thus, simple cognitive decision makers may unwittingly take more risks.

As mentioned before, committing false positives errors is the greater risk. In the context of this study, making the riskier choice would be to accept candidates and increase the chance of a false positive. Because cognitively complex individuals will have more awareness, they will be less likely to take risks. In other words, they would be less likely to accept the candidates and seek to reduce false positives. Therefore:

H5b: Participants with high scores on cognitive complexity will be less likely to take risks and thus avoid false positive errors when selecting candidates.

Personality. Although personality is not new to personnel selection, its use had diminished throughout the 1970s and 1980s because of lack of critical support for their use as predictors of performance. Its use in selection however has enjoyed a resurgence primarily due to the emergence of the Big Five Factors of personality as a wellrecognized framework onto which various personality scales can be mapped.

Additionally, the Big Five Factors allowed the use of meta-analytic techniques to a disjointed personality validity literature (Ones \& Viswesvaran, 1997). The Five Factors derive from a lexical tradition that believes one should be able to identify the structure of personality traits by analyzing the adjectives that people use to describe themselves (Dalton \& Wilson, 2000). The factors are emotional stability (tendency to experience 
negative affect such as fear, sadness, anger, guilt), extraversion (tendency towards sociability, assertiveness, being talkative), openness to experience (describing those willing to entertain novel ideas and unconventional values), agreeableness (describing traits such as sympathy, cooperativeness, helpfulness towards others), and conscientiousness (tendency towards achievement, order, dutifulness, self-discipline) (Dalton \& Wilson, 2000).

In the validity literature, there is ample evidence of personality variables as legitimate predictors of job performance. Barrick and Mount (1991) reported the validity coefficient for conscientiousness to be higher than .20 . Other researchers have also concluded personality variables to be valid predictors of performance and thus valuable predictors in selection (Ones, Viswesvaran \& Schmidt, 1993; Salgado, 1997). In their review of the personnel selection literature, Schmidt and Hunter (1998) list the validity coefficient for conscientiousness at .31 and its incremental validity over cognitive ability as a predictor of job performance at .09 or $16 \%$. Aside from being a good predictor of job performance, personality operationalized in the form of the Big Five has been useful to consider alongside cognitive ability because for the most part they are uncorrelated with each other (Ackerman \& Heggestad, 1997). Likewise, in this study, it may be useful to consider the Big Five alongside cognitive complexity as they may also have little correlation to each other.

Additionally, there is evidence of personality affecting individual decisionmaking. For example, in the vocational counseling literature there is evidence of a relationship between personality and vocational interests (Five Factor Model and Holland's RIASEC model of occupational identity). In a meta-analysis, Larson, 
Rottinghaus, \& Borgen (2002), found statistically significant correlations between the two models (i.e. correlations between Artistic interests and Openness to Experience). In other words, people base their occupational choices on their different interests, which in turn are affected by their personality profiles. Sears and Rowe (2003) examined whether rater-applicant similarity in terms of personality (conscientiousness) moderated interview ratings. Results showed similar-to-me effects for competence ratings and judgments of overall job suitability for high conscientious raters. Highly conscientious raters evaluated highly conscientious candidates more favorably. Unlike conscientious raters, raters low on conscientious did not differentiate between candidates, giving similar ratings to candidates regardless of the candidate's level of conscientiousness.

Another study examined the differences in personality dimensions and entrepreneurial status. Zhao and Seibert (2006) found entrepreneurs and managers significantly differed in four of the five personality dimensions of the Five Factor Model. The authors purposefully compared managers to entrepreneurs because they believed the similarities between the groups would provide a rigorous comparison. Nevertheless, the groups differed in personality characteristics, further supporting the idea that personality differences affect people's decisions. The research on personality in this study is somewhat of an exploratory nature. I explore each factor individually.

Extraversion. Extraversion typically describes the degree to which people are assertive. Extraverted individuals are typically seen as outgoing, talkative, assertive and excitement seeking. Low scores on extraversion have been associated with traits such as being reserved and cautious. In making decisions, extraverted individuals may be more impulsive and thus not take as much time to understand and perceive the cues presented. 
In contrast, an introvert is typically more analytical before speaking and thus by thinking each scenario through, might be more aware of the cues presented. The increased cue awareness will increase the likelihood cue usage.

H6a: There will be a negative correlation between extraversion and cue usage when selecting candidates.

Some researchers have explored the relationship between personality and risk taking behavior. More specifically, they have looked at the relationship between extraversion and risk taking. Kowert \& Hermann (1997) found a positive correlation between excitement seeking (a facet of extraversion) and risk taking. Another study found that of the Big Five facets, sensation seeking had the strongest relation to risk taking (Nicholson, Fenton-O’Creevy, Soane, \& Willman, 2004). As mentioned before, false positives (accepting a bad candidate) are riskier than false negatives (rejecting a good candidate). Thus, a willingness to make false positive errors is interpreted as a risk taking behavior. Because of their excitement seeking nature, extraverted individuals are more likely to take risks and thus accept false positives. On the other hand, because introverted individuals will be cautious and will make the safest decisions possible, they will become reluctant to make false positive errors. Hence:

H6b: Participants with high scores on extraversion will be more likely to take risks and thus place less importance on avoiding false positives when selecting candidates.

Agreeableness. Agreeableness assesses a person's interpersonal orientation. Individuals scoring high on agreeableness are characterized as trusting, altruistic and gullible (Zhao and Seibert, 2006). Moreover, agreeableness has been associated with 
traits such as flexibility, generosity, tolerance and sympathy (Digman, 1990). Agreeable individuals are more compassionate as opposed to antagonistic. Someone scoring low on agreeableness is suspicious and self-centered. Additionally, agreeable individuals are not always looking out for their best interest and as a result may be looking to include as many candidates as possible. McClelland and Boyatzis's (1982) showed that a high need for affiliation, a component of agreeableness, could be detrimental to managers as it interferes with the manager's ability to make difficult decisions affecting subordinates and coworkers. Finally, agreeable individuals are more likely to be concerned with compliance and thus might be more willing to use cues in efforts to find opportunities for inclusion of candidates when appropriate. Therefore:

\section{H7a: There will be a positive correlation between agreeableness and} cue usage when selecting candidates.

Agreeable individuals are typically altruistic and thus may be concerned about candidates' well-being. This in turn can lead a propensity to accept false positives and engage in risk taking behavior. Moreover, because agreeableness involves flexibility, it would seem likely for agreeable individuals to engage in risk taking behavior. Having low agreeableness would protect against the consequences of being tough on others. Low agreeableness would provide the needed tough-mindedness and a general lack of interest in others around you to take make decisions comfortably. Thus, agreeableness would probably relate to risk taking. In this context, it would increase the willingness of false positives. Hence: 
H7b: Participants with high scores on agreeableness will be more likely to take risks and thus place less importance on avoiding false positives when selecting candidates.

Conscientiousness. Conscientiousness indicates a person's level of hard work, motivation and persistence (Zhao and Seibert, 2006). Conscientiousness also reflects the extent to which someone is organized, deliberate, and methodical (Zhao and Seibert, 2006). Conscientiousness implies the use of a more systematic, conforming and calculating approach to work. Like cognitive complexity, it seems plausible that conscientious people are more attentive to the cues presented in this study. Additionally, because conscientious individuals will be more thorough and systematic in their task, they will effectively consider each factor when making decisions and attend to the cues. Therefore:

H8a: There will be a positive correlation between conscientiousness and cue usage when selecting candidates.

High scores on conscientiousness exemplify organization and careful planning before making decisions. Highly conscientious individuals also tend to be less lenient than their less conscientious counterparts, suggesting conscientiousness will correlate with avoiding false positive errors. Moreover, low scorers on conscientiousness can be quick to act and not consider consequences. Kowert and Hermann (1997) found a significant relationship between low scores on the conscientiousness factor of personality and risk taking. Low scores on conscientiousness also entails a lack of discipline which in turn can be related to risk taking behavior. Low conscientiousness will be associated with risk-taking and thus increasing the likelihood of false positives. Hence: 
H8b: Participants with high scores on conscientiousness will be less likely to take risks and thus place more importance on avoiding false positives when selecting candidates.

Openness to experience. High levels of openness to experience is characteristic of someone who is intellectually curious, seeking new experiences and exploring fresh ideas (Zhao \& Seibert, 2006). Low scores in openness are consistent with being conventional, narrow-minded and non-analytical. Being open to experiences implies being investigative which might lead to a greater perception of the cues presented. Additionally, openness implies trying different ideas and being comfortable with uncertainty. However, being open in making decisions does not mean making reckless decisions. Although individuals scoring high on openness may be willing to deal with uncertainty and be creative thinker, they will do so when appropriate. Accordingly, they will make greater use of the presented cues. Therefore:

H9a: Decision makers with high scores on openness will have higher cue usage when selecting candidates.

Kowert and Hermann (1997) found a strong positive relationship between openness to experience and risk taking. Individuals with high scores on openness to experience are characterized by wanting to try new activities, having a high tolerance for uncertainty and a preference for novelty. These characteristics could serve as precursors and possibly motivators for risk taking. It seems likely that those decision makers with higher levels of openness are comfortable with risks and are more likely to make riskier decisions. In the context of this study, this means taking risks with candidates and being comfortable with false positives. Hence: 
H9b: Participants with high scores on openness will be more likely to take risks and thus place less importance on avoiding false positives when selecting candidates.

Emotional stability. A low level of emotional stability implies feeling negative emotions such as depression, anxiety and insecurity. Individuals scoring low on emotional stability will be inclined to experience a number of negative emotions including hostility, and vulnerability. Low scores on this factor corresponds with being prone to worry, fear, and impulsiveness. In this case, impulsiveness refers to difficulty controlling urges and being spontaneous. Because of their hostility, individuals with low emotional stability will ignore the cues presented and simply act impulsively to reject candidates. Therefore:

H10a: Decision makers with low scores on emotional stability will have lower cue usage when selecting candidates.

High scores of emotional stability indicate being emotionally stable and calm even in stressful and ambiguous situations. Moreover, lower levels of anxiety and less worrying probably help in dealing with the possible negative outcomes and fears involved with risk taking. Having strong emotional stability can serve as a buffer to the anxiety brought by taking risks. Additionally, being emotionally stable implies resilience and self-confidence. These characteristics are probably essential for people who willingly engage in risk taking behavior. Thus, it seems likely that individuals with low scores on emotional stability would be less likely to engage in risky behaviors and would seek to reduce false positives. Hence: 
H10b:Participants with high scores on emotional stability will be more

likely to take risks and thus place less importance on avoiding false positives when selecting candidates.

The current research explores how individuals make personnel decisions. Researchers have shown that individuals do not have good insight into their own decision making process (Dunn et al., 1995; Moy \& Lam, 2004), even if respondents typically believe they do. To overcome this potential bias or limitation, and better understand how people are making decisions, a policy capturing study was developed. This dissertation continues by presenting the policy capture study used to examine the hypothesis presented. I follow this with an overview of the scale development, instruments used, participants and procedures for data collection. 


\section{Chapter III}

\section{Methodology}

\section{Policy Capturing}

In this study, I used a policy capturing method to examine the impact contextual factors have on decision makers. In using policy-capturing studies, the main goal is to understand how individuals make decisions given the information presented to them. The policy capture method presents decision-makers with situations where levels of the predictor variables (called cues) presumed to influence decisions are varied (Kline \& Sulsky, 1995). Participants then make judgments and through regression, it is determined how individuals made decisions. The statistical equation resulting from the regression analysis represents the captured rating policy for each decision-maker (Johnson, 2001). Stated differently, the regression equation is a depiction of the way in which information is combined and weighted to make decisions (Johnson, 2001). The purpose of this approach is to identify systematic statistical relationships between the judgment or decision and the information cues that were the basis for the judgment. By employing this methodology to investigate the importance placed on avoiding false positives in making selection decisions, issues of socially desirable responding can be minimized.

Given that the purpose of this study was to increase understanding of decisionmaking in selection, employing a policy capturing study made sense. When compared to direct self-report methods, policy-capturing methodology can result in greater accuracy of responses because of respondent impression management. Moreover, previous research has shown a discrepancy between factors respondents believed were important and factors that actually were important in making decisions or ratings (e.g., Dunn et al., 
1995). Policy capturing is widely accepted and has been used across many studies. For instance, policy-capturing studies have explored the relationship between predictors and the selection preferences of decision makers (Dunn et al., 1995; Moy \& Lam, 2003; Ones \& Viswesvaran, 1999). The present study, however, is different in that it used a policy capturing approach to study the impact of contextual factors in the selection process (environmental, job characteristics).

The policy capturing scenarios used in this study manipulated levels of four cues representing contextual factors. These were: (a) applicant pool, referring to the number of openings a job had and how many qualified candidates had been selected; (b) safety concerns, referring to whether or not a job involved the safety of others; (c) wage, referring to high versus low paying jobs; (d) job complexity/training requirements, referring to how much training a job required. This resulted in 16 "jobs" or scenarios (2 $\mathrm{x} 2 \times 2 \times 2$ ) for which decision makers determined the likelihood of selecting a candidate. The study used correlational and regression analyses to examine the relationship between these factors and decisions regarding candidates applying for the "jobs." Additionally, the study included four duplicated scenarios to test intra-rater reliability. These repeated ratings provided a measure of stability, or the consistency with which individuals formed their judgments.

Scenario development. The first step in developing the scenarios was to create a list of jobs that would fit the criteria for the study. For example, to have individuals making selection decisions for jobs having high educational requirements (e.g., lawyer), specific licenses (e.g., pilot), and/or highly specialized training (e.g., astronaut) would be completely off base and unrealistic. A list of 35 job titles was created to represent 
different levels (high/low) of the cues representing contextual factors (see appendix A). The next step was to ensure these job titles were consistent with people's perceptions of those jobs. Ensuring jobs fit the intended direction (high or low) of the cue it represented could help ensure more realism. To determine if these jobs represented the cues as intended, ten graduate students rated the job titles. Participants rated the jobs as either high or low in terms of safety concerns, wage, and training requirements. Because the selection ratio or number of available candidates for a job is not inherent to the job itself, applicant pool was not assessed. So, if a job purported to represent a job that was high paying, involved the safety of others and required little training/skill development, individuals making decisions should perceive it in this manner. The criterion used was that at least 6 out of 10 raters would have to agree on whether a job was high/low for any given cue.

On the basis of the input provided by the respondents, 20 jobs were chosen for the policy capturing study (see appendix B). These jobs represent different combinations of the cues assessed. Fourteen of the twenty jobs chosen complied with having at least $60 \%$ of the raters agreeing on whether the job was high/low for all of the cues. Six jobs had only $50 \%$ of the raters endorse it in the expected level of the cue, all of them in the training/complexity cue. Raters were split on whether they thought the job had high or low training needs. Even though these jobs did not meet the $60 \%$ decision rule, they were kept for three reasons. First, they were close by having at least $50 \%$ of the raters endorse them in the expected cue. Secondly, the jobs had the right combination of high/low on other cues needed for the study. Finally and most importantly, the job information being provided as part of the job descriptions used in the policy capture 
study, included specific training requirement. Therefore, although everyone might not initially perceive a job as having high/low training requirements, this information would actually be there when participants made decisions.

\section{Participants}

Two samples were used to test the hypotheses proposed in this study. The first sample consisted of 104 students enrolled in a large, southeastern university. Two respondents did not provide complete data and were eliminated from the sample. This first sample thus consisted of 102 participants $(79 \%$ female, mean age $=22$ years and SD =4.48). Participants were $81 \%$ Hispanic, 5\% Black, $6 \%$ White, and $8 \%$ indicated "other." Sixty-five percent of the students reported working at least part-time and 86\% reported having gone through at least one job interview in the past. Fifty-four percent of the respondents reported having been involved at least once in a selection process (recruiting, interviewing and/or selecting candidates). However, only $13 \%$ had engaged in a selection process on more than 3 occasions. Finally, 17\% reported having witnessed a serious accident at work and 19\% reported having worked in an environment they perceived dangerous. All students were in psychology classes and participated in exchange for credit in their class. Students participated via the Sona System at http://fiu.sona-systems.com. Sona is an automated system accessed directly by students in order to sign up for experiments and receive extra credit toward their classes. Data collection for this study was conducted over the Web, so participants who logged into the Sona System and signed up to participate, were given the URL to the study materials.

The second sample was a national sample of 208 participants. Sixty-five respondents (31\%) did not complete the required study materials and were eliminated 
from the study. The second sample thus consisted of 143 respondents $(68 \%$ female, mean age $=43.74, \mathrm{SD}=13.01$ ). Participants in this second sample were $70 \%$ White, 13\% Hispanic, 8\% Asian, 4\% Black and 6\% indicated "other." Thirty-nine percent $(\mathrm{n}=$ 56) of respondents indicated they had at least a Bachelor's degree while $71 \%$ had at least completed one year of college. Sixty-two percent of participants reported working at least part time with the majority being employed full time (72\%). Virtually all participants (99\%) reported having gone through at least one job interview in the past while $56 \%$ reported having been involved at least once in a selection process (recruiting, interviewing and/or selecting candidates). In fact, $34 \%$ of respondents indicated having participated in a selection process more than 3 times. Finally, 12\% reported being involved in a past serious accident at work while $24 \%$ had witnessed a serious work accident. Forty percent of respondents also reported having worked in an environment they perceived as dangerous.

Recruiting for participants in the second sample took place through an online participant pool (Study Response Project, SRP), which operates out of Syracuse University in Syracuse, NY. The Study Response Project is an academic research project connecting researchers with individuals wanting to participate in research. The Study Response Project only works with individuals who are over the age of 18 and have given their consent to participate in such research. It contains a database of tens of thousands of potential participants who have agreed to participate in Web-based research projects. The Study Response Project e-mailed a solicitation to randomly selected e-mail addresses from their database including the link to the study. Researchers pay a fee for SRP to send solicitations, and from this licensing fee, funds are devoted to compensating participants 
through gift certificates for Amazon.com. All participant personal information is kept by SRP and it is not available to researchers. For this study, participants entered their Study Response Identification. The researcher then sent a list of the SRP numbers entered by participants to SRP and they conducted a drawing and awarded the certificates.

Because the samples were recruited from different populations and areas (current college students versus national sample), differences were expected across samples in several demographics. The national sample had a higher mean age (44 versus 22$)$, a higher percentage of college graduates (37\% versus $9 \%$ ), and a higher percentage of fulltime employees ( $45 \%$ versus $17 \%$ ) than the college sample. Additionally, because the student sample was from a major Hispanic city, ethnicity was vastly different when comparing the samples. Specifically, $81 \%$ of respondents in the student sample were Hispanic as opposed $13 \%$ in the national sample. Gender distribution was more consistent across both samples, although the student sample had a slightly higher percentage of women in the sample ( $79 \%$ versus $68 \%)$.

\section{Measures}

Policy capturing scenarios. Participants assumed the role of a "Personnel Recruiter" in a staffing company. The participants' task was to read 20 scenarios containing a job description that included whether the job had many remaining openings, involved the safety of others, had high/low training requirements, and had a high/low salary. Additionally, participants received applicant information about a group of candidates (borderline passing candidates; Appendix C). Following each job description participants indicated the likelihood of passing a candidate from the low scoring group to the next phase in the selection process. In this particular study, lower scores reflected a 
less likelihood of hiring a candidate. Not passing a candidate in turn was indicative of placing a greater importance on avoiding false positives. Therefore, if a decision maker was more concerned with reducing false positives, the likelihood of moving a candidate would be lower. A sample from the policy capturing scenarios appears below.

Position: Telemarketer - Solicit orders for goods over the telephone.

\# of candidates needed: 14

\# of candidates already forwarded: 5

Salary: $\$ 9.75$ hourly; $\$ 20,280$ annual

Tasks:

- Deliver prepared sales talks describing products to persuade potential customers.

- Contact businesses by telephone to solicit sales for goods or services.

- Obtain customer information and enter orders into computers.

Job Training Needed: Low ( 0 to 3 months of training)

How likely are you to recommend a candidate from Group 1 for this job?

$\bigcirc$ very unlikely $\bigcirc$ unlikely

Somewhat

somewhat

Likely Likely

Very Likely

Cognitive complexity. Cognitive complexity was assessed using a reduced 4 × 6

version of Bieri et al.'s (1966) repertory grid technique (Appendix D). Participants were asked to make ratings on four role types (mother, friend of opposite gender, person with whom you feel most uncomfortable, and supervisor or boss) on six-point bipolar constructs (outgoing-shy, adjusted-maladjusted, decisive-indecisive, calm-excitable, interested in others-self absorbed, and cheerful-ill humored). Therefore, the test consisted of a 4 x 6 grid where participants made six ratings for each of the four role types. The figure below illustrates the grid used in this study. 
Starting with the first word pairing (outgoing-shy), rate each person using the continuum provided.

For example if you feel the person you are describing is very outgoing then you may choose a rating of $1 \mathrm{~L}$. On the other hand, if a person is somewhat shy, you would choose a rating of $2 \mathrm{R}$.

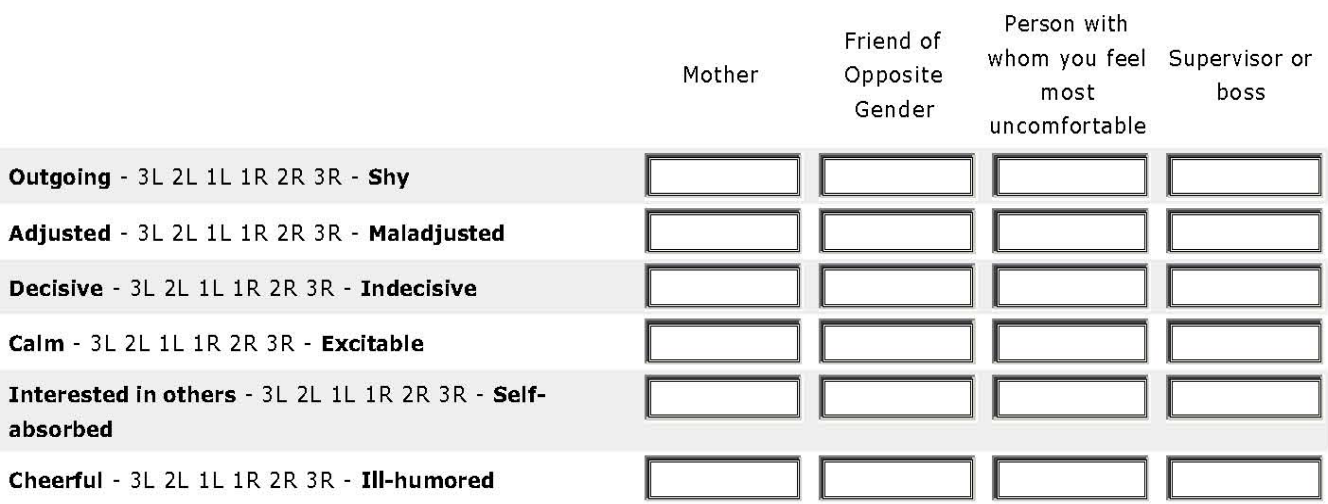

Level of cognitive complexity was determined by comparing ratings used in each

role type. The number of redundant ratings across constructs gauged cognitive

complexity. Having many similar ratings for the same role (person) was indicative of low cognitive complexity. Rating people with dissimilar ratings implied higher levels cognitive complexity because of the inferred multi-dimensionality of the individual's ratings (Bieri et al., 1966). A score on the measure is obtained by summing the number of matching ratings given to the same role type. More specifically, each rating in a column is compared with all of the ratings below it. Identical ratings within the same column (role) are scored as 1 and non-identical ratings scored 0 . This matching procedure is carried out for all possible comparisons in a column. Because each role allows for 15 comparisons of ratings, cognitive complexity scores ranged from $0-15$ for each role type indicating the number of repeated ratings within the role. Since there were four role types on this test, overall scores could range from 0 (indicative of very high 
cognitive complexity because no ratings were repeated in any role) to a ceiling of 60 (indicative of very low cognitive complexity). To assist interpretation, scores were recoded so that higher scores indicated greater cognitive complexity. Additionally, bipolar constructs with ratings in alphanumeric symbols (3L, 2L, 1L, 1R, 2R, and 3R) were used to reduce social desirability and possible halo effect.

Evidence of the reliability for the repertory grid technique used to assess cognitive complexity has been favorable. Tripodi and Bieri (1963) reported 1-week test-retest reliabilities for a $10 \times 10$ assessment ranging from .71 to .86 . Spengler \& Strohmer (1994) reported 1-week test-retest reliabilities for the reduced version used in this study at .82. Additionally, the $4 \times 6$ version used in this study was found to produce complexity scores that were correlated with scores derived from Bieri's 10 x 10 version (r $=.89$ ), suggesting the measures are comparable (Spengler \& Strohmer,1994).

Personality. The Big Five personality factors were assessed through the International Personality Item Pool (2001) found online at http://ipip.ori.org. Participants indicated the accuracy of 50 statements in describing themselves using a 5-point Likert scale ranging from very inaccurate to very accurate (Appendix E). Rationale and further explanations can be found at their website at http://ipip.ori.org/ as well as Goldberg (1999). The measure is psychometrically sound having coefficient alphas reported on their website (http://ipip.ori.org/ipip/new_home.htm) ranging from .79 to .87 for the scales.

Demographics. Participants also completed a demographics survey asking gender, ethnicity, age, student and employment status, GPA and educational level. As previously discussed, the samples differed in several of these demographic variables (i.e., 
age, ethnicity). Additional information was gathered regarding the participants' experience in the selection process as either a candidate and/or a decision maker. Finally, participants were also asked if they were ever involved in or witnessed a serious accident at work (Appendix F).

Again, and not surprisingly the two samples differed in their responses to some of these additional demographic variables. Although almost everyone in both samples had interviewed for a job at least once, the average number of interviews differed across samples. In the national sample, the average number of job interviews participants reported having gone through was almost 10 . This was nearly triple the average reported by the student sample (3.80 interviews). Additionally, the number of people who reported never being part of a selection process (i.e. interviewing candidates) was slightly higher for the student sample ( $45 \%$ versus 39\%). However, the percentage of people who reported being part of a selection process four or more times was considerable larger for the national sample (34\% versus $13 \%)$. It seems both samples have experienced the selection process at least once in similar proportions. However, as expected, because of the age difference in the two samples, the national sample has greater experience in the selection process as a candidate and an interviewer.

Regarding accidents at work, $12 \%$ respondents from the national sample reported having been in a serious accident at work, compared to only $3 \%$ of respondents from the student sample. Respondents from the national sample also reported having witnessed more accidents at work than respondents from the student sample ( $24 \&$ versus $17 \%$ ). Finally, $40 \%$ of respondents from the national sample have worked in an environment they considered dangerous whereas only $19 \%$ of the student sample indicated this to be 
the case. These differences are again likely the result of the age difference in the two samples. Because of this age difference, respondents from the national sample have had more jobs, more experience in selection, have had or witnessed more accidents in the work place and have held more jobs that are dangerous. Further analysis discussed later helps determine if the differences in the experience of respondents actually led to disparate findings for the two groups.

Manipulation check. Participants completed a short questionnaire to determine if they correctly interpreted the cues, job descriptions and the intended task of the policy capturing study (Appendix G).

\section{Procedure and Data Analysis}

A policy capturing was designed to explore the relative importance job factors and individual difference variables have on selection errors. Participants responded to scenarios manipulating two levels of the four job characteristics discussed (resulting in 20 scenarios). Additionally, respondents completed a measure of cognitive complexity, a measure of the Big Five Factors of personality, a demographic survey and a short manipulation check measure. This took approximately 45 minutes to complete.

The variables in the study were all recoded to facilitate interpretation of scores. In order to interpret the beta weights and relate them to other variables of interest (i.e., gender, race, and previous experience in selection), each variable was recoded as either zero or one consistent with its expected direction in relation to the dependent variable. The dependent variable asked participants to rate the likelihood of moving on a candidate using a scale of one to six. Because of this, answering on the lower end of the scale meant it was unlikely the participant would move the candidate along in the process. So 
for example, jobs having high training needs were coded as zero since it was expected that when selecting for jobs with high training needs, candidates would be using the lower end of the scale. Conversely, it was expected that when selecting for jobs with low safety concerns, candidates would be using the higher end of the scale. Thus, jobs having low safety concerns were coded as one. This table summarizes the coding scheme used regarding the cues and demographic variables collected.

\section{Coding Scheme}

\begin{tabular}{|l|ll|}
\hline DV = Likelihood of passing candidate & \multicolumn{2}{|c|}{1 (Very Unlikely) through 6 (Very Likely) } \\
\hline Applicant Pool & 0 - Low \# of candidates needed $\begin{array}{c}1-\text { Many candidates } \\
\text { needed }\end{array}$ \\
\hline Security Conditions & $0-$ High safety concerns & $1-$ Low safety concerns \\
\hline Training Requirements & $0-$ High & $1-$ Low \\
\hline Wage & $0-$ High & $1-$ Low \\
\hline Job status & $0-$ Fulltime/part time & $1-$ Unemployed \\
\hline Job Interview participation (interviewed) & $0-$ Yes & $1-$ No \\
\hline Selection Process Participation & $0-$ Yes & $1-$ No \\
\hline $\begin{array}{l}\text { Selection Participation } \\
\text { Frequency(selecting) }\end{array}$ & $0-$ Often & $1-$ Rarely \\
\hline Student Status & $0-$ Full time & $1-$ Part time \\
\hline Race (Hispanic or not) & $0-$ Non-Hispanic & $1-$ Hispanic \\
\hline Gender & $0-$ Male & $1-$ Female \\
\hline Witness accident at work & $0-$ Yes & $1-$ No \\
\hline Work in dangerous environment & $0-$ Yes & $1-$ No \\
\hline
\end{tabular}

A reliability analysis was first performed for the personality measure. Next, the samples were compared on the variables of interest to determine if they could be combined for further analyses. Regressions were then ran for each participant to determine the importance they placed on each job characteristic. The proposed hypotheses were subsequently tested using the four beta weights acquired from these analyses and the individual differences measures used (personality and cognitive complexity). 
The study used correlational and regression analysis to determine the importance placed on each job characteristic. The four characteristics (applicant pool, safety concerns, training requirements and salary/wage) were the independent variables while the judgments (likelihood of moving candidate along in the selection process) served as the dependent variable. In this study, not moving a candidate along the process would suggest an individual was placing greater importance of avoiding false positives. To test hypotheses 1 through 4, the judgments or likelihood of hiring were regressed on the cues to determine the policy used by decision makers. The four standardized beta weights reflected the importance placed by each individual on the cues. Lower beta weights indicated participants placed less value on the cues presented. Conversely, having a positive high beta weight was indicative of the influence of that specific cue. Therefore, if a participant had a high positive beta weight for safety concerns, the likelihood of moving along a candidate for jobs having high safety concerns was low and thus more importance was placed on avoiding false positives. The relative weight placed on the job characteristics in fact determines the effect of these characteristics on decision-making. The $\mathrm{R}^{2}$ indicated the amount of variance in the decision to hire explained by a set of cues. After obtaining the relative importance placed by participants on each of the cues presented, a meta-analysis was completed. Eight separate meta-analyses were completed (one for each cue) to determine if the relative importance of the cues varied by participants. Applying Hunter-Schmidt's framework (Hunter \& Schmidt, 1990), the standardized beta coefficients for each cue across all participants were meta-analyzed. First, the observed variance was computed. The variance due to sampling error was then 
subtracted to obtain the residual variance. If respondents used different policies in making decisions, the residual variance would be greater than zero.

Hypotheses 5-10 were tested using correlational analysis. First, correlations between R-square and personality and cognitive complexity were computed for both samples. The R-square for each participant serves as an indicator of how much of the participant's policy was captured by the cues. That is, the $\mathrm{R}^{2}$ describes how much of the variance in a participant's likelihood of selecting a candidate is explained by the cues used. Thus, correlating R-square to personality and cognitive complexity helps determine if participants' individual differences influenced their use of cues when making decisions. A second set of correlations for personality and cognitive complexity was completed using the participants' overall likelihood of accepting (rejecting) the candidate. The average of decisions made by each participant across all jobs was computed and then correlated to their personality and cognitive complexity scores. Participants were asked to make a judgment on a borderline candidate. Because of this, the overall likelihood of moving a candidate along serves as an indicator of how much a participant is avoiding false positives. Put differently, the more likely you are to accept a borderline candidate, the more likely you are to have a false positive. Thus having an overall low likelihood of accepting the candidate across all jobs is an indicator of avoiding false positives.

This dissertation now moves to the results section. The results section begins with an independent sample $t$ test comparing the two samples to determine if it is appropriate to combine the samples for analysis. Next, evidence of reliability for the 
measures used is presented. A discussion on the manipulation check used in this study follows the reliability analysis. Lastly, I discuss the results for the hypotheses tested. 


\section{Chapter IV}

\section{Results}

Independent-samples t-tests were completed to determine whether data from both samples could be analyzed together. Means were compared from both samples across the variables of interest and demographic variables. Results showed the Study Response (M $=3.70, \mathrm{SD}=.59)$ and student sample $(\mathrm{M}=3.94, \mathrm{SD}=.47)$ significantly differing on their level of openness to new experience $t(239)=3.62, p<.01$. Moreover, the samples differed in several demographic variables such as age, gender, ethnicity, number of times going through a job interview, number of accidents at work, witnessing accidents at work, and having experienced working in a dangerous environment. Table 1 presents the results of the t-test analyses comparing both samples across personality, cognitive complexity, and demographic variables.

Of particular concern was the differences found between the samples on some of the demographic variables. For example, the mean age of the student sample was approximately 22 years of age while the SR sample was close to 44 . Another difference was in the number of job interviews the respondents indicated they had gone through. The student sample participants reported having gone through an average of about 4 interviews while the SR participants reported close to 10 interviews. This clearly suggests there should be considerable difference in workplace experience between the two samples. A large difference in experience can in turn impact decision making. Because of these differences as well as others found and reported in table 1, all analyses were conducted on the student and Study Response samples separately. 
A reliability analysis was completed for the policy capturing scenarios presented to the study participants. Of the 20 scenarios, sixteen were unique combinations while the remaining four scenarios were duplications used to examine the consistency of decision makers. The correlation between these repeated pairs was used as a measure of reliability. In other words, were respondents making consistent decisions when presented with identical scenarios (same combination of high/low salary, training requirements, etc.). The correlation between the responses to the duplicated job scenarios was computed (i.e., correlation between job 1 and its duplicate job 17). Using four duplicate scenarios and comparing them to their similar counterpart yielded 980 paired comparisons across both samples $(\mathrm{n}=245)$. The computed correlation for these four duplicated scenarios was .58 for the combined sample. One particular duplicate yielded very low correlations and when removed from the intra-rater calculation, the correlation between the duplicate scenarios increased to .78 . These results suggest decisions were made with some degree of consistency.

Reliability analysis was completed for the personality scales using Cronbach's alpha. For the student sample, the reliability of the scales for the student sample were conscientiousness $\alpha=.78$, agreeableness $\alpha=.77$, neuroticism $\alpha=.84$, extraversion $\alpha=$ .85 and openness to experience $\alpha=.54$. With the exception of openness to new experience, all the scales yielded scores consistent with good internal consistency. Two items were removed from the openness to experience scale in the student sample, resulting in an eight-item scale with $\alpha=.64$. In the StudyResponse (SR) sample, all scales had good internal consistency, requiring no modification to the original scales. 
Results for the SR sample were conscientiousness $\alpha=.82$, agreeableness $\alpha=.81$, neuroticism $\alpha=.89$, extraversion $\alpha=.87$ and openness to experience $\alpha=.78$.

To verify if participants correctly interpreted the cues, job descriptions and the intended task, participants completed a short questionnaire (Appendix G). Two questions asked participants to identify information presented during the study. Participants were asked to select from a list which characteristic was not included in the job descriptions presented. Seventy-nine percent of respondents correctly indicated that job descriptions did not contain information regarding minimum educational requirements. A second question asked participants to indicate from a list, for which group of candidates they were making decisions (borderline passing candidates). Eighty-two percent correctly identified the borderline passing group as the group from which they were making decisions. These results suggest participants were aware of the cues as presented in the job descriptions. Likewise, respondents were aware of the group of candidates for which they made decisions.

Additionally, respondents received four job titles from the jobs presented earlier and were asked to rate the jobs as either high/low in regards to safety concerns, complexity/training needs and salary. Participants thus made 12 responses (four jobs and three characteristics). More than $80 \%$ of participants correctly identified whether the job presented was high/low in a given characteristic for 10 of the 12 responses. The remaining two were interpreted correctly by $71 \%$ and $63 \%$ of the respondents. Again, results indicate that participants understood the information presented to them regarding the jobs and their task.

\section{Importance Placed on Job Characteristics}


The first four hypotheses predicted that individuals making decisions on jobs with a high number of available candidates, high safety concerns, high salary and high training requirements, would place more importance on avoiding false positives. Thus, these individuals would be less likely to move a borderline candidate along the selection process. The importance placed by individuals on the 4 job characteristics or cues was assessed through several regression analyses.

The first analysis was to examine the relative weights of the cues across all participants. The average of the decision to move a candidate along (assessed on the 1-6 scale) was computed for each job profile (20 job scenarios) and regressed onto the cues (see table 2). For the student sample: $R^{2}=.73 ; F(4,15)=9.870, p<.000$. The beta weights for training requirements and wage were statistically significant. The largest standardized regression coefficient (beta weight) was for training requirements $(\beta=.60)$. Having high training requirements was the most important job characteristic in participants not moving a candidate along the selection process and thus avoiding false positives.

The second most important cue was the wage of a job $(\beta=.49)$. For jobs having a higher salary, respondents were less likely to move candidates along the selection process and so more concerned with avoiding false positives. The regression weights for security concerns $(\mathrm{B}=.19)$ and applicant pool $(\mathrm{B}=-.03)$ were not statistically significant. Participants did not appear to be worried about avoiding false positives for jobs involving the safety of others or jobs having a low selection ratio.

Similar results were obtained for the SR sample: $R^{2}=.77 ; F(4,15)=12.246, p<$ .000 (see table 3). For this sample, however the beta weight for security concerns was 
also statistically significant along with training requirement and wage. The largest regression weight was for wage $(\beta=.53)$. The second most important cue in this sample was training requirement $(\beta=.52)$. The third most important cue for the SR sample was security concerns $(\beta=.34)$. It appears that unlike the student sample, participants in the SR sample were affected by the safety implications of a job when making their decisions. For jobs involving the safety of others, participants in the SR sample were less likely to move the candidate along and thus were more concerned with avoiding false positives. Finally, participants in this sample were not concerned with the selection ratio regarding the applicant pool of a job when making their selection decisions.

The second analysis completed to test hypotheses 1-4 involved computing a regression for every respondent using the 20 scenarios as cases. That is, 102 regressions were completed for the student sample while 143 for the SR sample. The judgment of passing the candidate along in the selection process (assessed on the 1-6 scale) served as the dependent variable. By regressing the judgment on the four cues, the policy used by each decision maker was established. The beta weights resulting from this regression, serve as an index of how important each cue was to that participant when making decisions. The mean standardized regression coefficients (beta weights) are presented in Tables 4-5. After obtaining the relative importance of each cue for all of the participants, the four standardized beta weights were analyzed in three different ways.

First, the percentage of significant standardized beta weights was calculated for each cue. That is, of the 245 (102 for the student sample and 143 for the SR sample) participants, how many had a statistically significant standardized beta weight in their regression equation. A statistically significant beta weight implies the cue was important 
when decision makers were evaluating candidates. For the student sample, the most important cue was training requirement, which had a statistically significant beta weight in $52 \%$ of the respondents. Training was followed by wage ( $49 \%$ of respondents), security concerns (13\%) and applicant pool (1\%). For the SR the most important cue was wage, which had a statistically significant beta weight in $45 \%$ of the respondents. Wage was followed by training requirement ( $41 \%$ of respondents), security concerns $(25 \%)$ and applicant pool (2\%). Tables 6-7 summarize these results for the student and SR samples.

Secondly, a meta-analysis was completed to cumulate the standardized regression weights. Given four cues and two samples, eight meta-analyses were completed. Each meta-analysis contained either 102 estimates (for the student sample) or 143 estimates (SR sample). Each estimate was based on the 20 judgments (jobs) made by each participant. First, the observed variance was computed. The variance associated with sampling error was then subtracted from the observed variance to obtain the residual variance. If participants use different policies when deciding to move a candidate along, the residual variance should be greater than zero. In other words, having a residual variance greater than zero, can help determine if the importance placed on the different job characteristics was due to participants' differences in cue usage and not statistical artifacts. The residual variance was greater than zero for five of the eight meta-analyses. In the student sample, the residual variance was greater than zero for training requirement .0755 and wage .0541 . In the SR sample, the residual variance was greater than zero for wage .0973 , training requirement .0673 , and security concerns .0080 . The residual variance for the applicant pool cue was not greater than zero for either sample. These 
results suggest the relative importance placed on at least some of the cues varied across participants. Table 8 presents these results for all the samples.

The final test with the standardized beta coefficients involved computing 95\% confidence intervals around the relative weights. The confidence intervals around each weight were computed using the standard error and multiplying it by \pm 1.96 . This methodology is consistent with Johnson (2001). Examining tables 9-10 shows the confidence intervals did not include zero for three of the four standardized beta weight across both samples. In other words, the mean standardized regression weights significantly differed from zero and thus the cues affected participants' decisions. Only the applicant pool cue included zero in its confidence interval for both samples.

In summary, the first hypothesis was not supported. Applicant pool available for a job did not produce significant results in any of the analysis completed. The betas in the regression equations were not significant, sample error explained all of the variance in the ratings made by participants, and its $95 \%$ confidence interval around the standardized regression weight contained zero. The second hypothesis was moderately supported, particularly in the Study Response sample. The beta weight was significant across all participants in the SR sample. Additionally, 25\% of the respondents in Study Response sample had a statistically significant beta for this cue. In other words, the security concern of a job was an important characteristic when making decisions. Finally, the $95 \%$ confidence interval did not include zero for either sample.

Results strongly supported hypotheses three. The training needs of a job was the largest regression weight for the student sample and second most important in the SR sample. Participants were evidently more selective and less likely to move a borderline 
candidate along the process when selecting for jobs having high training requirement. Additionally, nearly half of all respondents considered a job's training requirement an important job characteristic. A significant beta was part of the regression equation for $52 \%$ and $41 \%$ of the student and Study Response samples respectively. However, results of the meta-analyzed standardized coefficient betas revealed residual variance greater than zero suggesting some individual differences in the cue usage. Finally, a $95 \%$ confidence interval did not contain zero.

Likewise, hypothesis four was strongly supported. The wage of a job was the largest regression weight for the SR sample and second most important in the student sample. Nearly half of all respondents considered a job's wage an important job characteristic when making selection decisions. In other words, participants were more selective when making decisions about jobs having high versus low wages. A significant beta was part of the regression equation for $49 \%$ and $45 \%$ of the student and Study Response samples respectively. However, results of the meta-analyzed standardized coefficient betas revealed residual variance greater than zero suggesting some individual differences in the cue usage. Finally, a 95\% confidence interval around the regression weight did not contain zero.

\section{Tests of Hypothesized Relationships between Individual Differences and Relative}

\section{Weights}

The obtained beta weights and other individual differences measures (e.g., personality, cognitive complexity) were used to test the remaining hypotheses. Tables 1112 present the means, standard deviations, and intercorrelations of all variables of interest for the student and Study Response samples. Hypothesis 5a received no support as 
cognitive complexity was not related as expected to cue usage when making decisions. In fact, the relationship was significant in an opposite manner for the SR sample. That is, when making decisions, individuals with higher cognitive complexity made less use of the cues. Although the student sample did not produce similar significant findings, $r=-$ $.03, p>.05$, the results also failed to support the hypothesis. The evidence also failed to Hypothesis $5 b$. There was no relationship between participants' cognitive complexity score and their overall likelihood to move a candidate along the process.

Similarly, results did not support hypothesis six and findings were in the opposite direction. Individuals in the Study Response sample $(r=.14, \mathrm{p}<.10)$ with high scores in extraversion actually displayed a greater use of the cues when making decisions $(r=.14$, $\mathrm{p}<.10$ ). Although the correlations were not significant at .05, it bears mentioning since they contradict the expected relationship. No relationship was found between extraversion and the overall likelihood of selecting a candidate.

The seventh hypothesis predicted that agreeable individuals would make greater use of the cues in making decisions due to their flexibility, generosity and tolerance. Results offer partial support for this hypothesis. In the Study Response sample, a statistically significant relationship was found between the $\mathrm{R}^{2}$ and scores on agreeableness (Study Response sample, $\mathrm{r}=.18, \mathrm{p}<.05$. No significant results were found in the student sample for the relationship between cue usage and agreeableness, $r=$ .08. The data also failed to support hypothesis $7 \mathrm{~b}$ as there was no significant relationship between agreeableness and the overall likelihood of selecting a candidate in neither the student sample $(\mathrm{r}=.07)$ nor the SR sample $(\mathrm{r}=-.03)$. 
As evidenced from tables 11-12, hypotheses eight through ten received no support from the data. No significant relationships were found between cue usage $\left(\mathrm{R}^{2}\right)$ and conscientiousness in the student sample $(r=-.05)$ and Study Response sample $(r=.02)$. There was not a significant relationship between conscientiousness and the likelihood of moving a candidate along in the process in neither sample. Similar non-significant results were found for openness to experience and emotional stability and their relationship to cue usage and likelihood of moving a candidate along in the process.

The next analysis evaluated the relationship between individual differences and the cues used in the study. Correlations were computed between the big five factors, cognitive complexity and the obtained beta weights. In the student sample, none of the personality factors were significantly correlated to any of the beta weights. Cognitive complexity also showed no relationship to any of the standardized regression weights (see table 11 for complete results). In the SR sample, 7 of the possible 24 correlations were found to be significant (table 12). Specifically, the beta weight for applicant pool was significantly correlated to openness $(r=-.17)$ and agreeableness $(r=-.17)$. The beta weight for security concerns was significantly correlated to openness to experience $(\mathrm{r}=$ 20), agreeableness $(\mathrm{r}=24)$, and neuroticism $(\mathrm{r}=-.16)$. The beta weight for wage/salary was significantly correlated to openness $(r=.22)$ and agreeableness $(r=.19)$. Cognitive complexity was not significantly correlated to any of the beta weights (table 12).

Multiple regression analyses failed to establish cognitive complexity and personality as valid predictors in this study. None of the individual difference variables used in this study were significant predictors of $\mathrm{R}^{2}$ (cue usage) and risk taking (average likelihood of accepting a candidate across all 20 scenarios). Tables 13-16 provide the 
results of the multiple regression analyses for both samples. Similarly, cognitive complexity and personality also failed to be significant predictors of any of the obtained standardized regression weights (tables 17-18). The only exception was agreeableness, which was found to be a significant predictor of the standardized regression weight for security concerns. These results suggest that individual differences variables, such as personality and cognitive complexity have a limited role in affecting decision making in personnel selection.

\section{Exploratory Analysis}

Exploratory analyses were completed to further explore how individual difference variables might affect the importance placed on each job characteristic, cue usage and the likelihood of moving the candidate. Several demographic variables were recoded and their relationship to the study variables were explored. These demographic variables included age, gender, ethnicity, student status, job status, having witnessed a serious accident at work, having suffered a serious accident at work, and having been previously involved in a selection process.

For the student sample, only job status (recoded as working or not working) had a significant correlation to the beta weight for wage $(r=-.19, \mathrm{p}<.05)$. That is, unemployed participants were less likely to move candidates along the process for jobs having a high wage. No other significant correlation was found between the demographic variables, the standardized regression weights, and cue usage when making decisions.

In the Study Response sample, several demographic variables correlated to the variables of interest. Age was significantly correlated to $\mathrm{R}-$ square $(r=.24, \mathrm{p}<.01)$ 
suggesting that as participants got older, they made greater use of the cues presented. This was true particularly of the relative importance placed on security concerns $(r=.21$, $\mathrm{p}<.05)$ and wage $(\mathrm{r}=.28, \mathrm{p}<.01)$. Another significant finding involved ethnicity and the standardized regression weight for applicant pool cue. Ethnicity (recoded as 0 for non-Hispanic and 1 for Hispanic) was significantly correlated to the beta weight for applicant pool. In other words, Hispanics placed more relative importance on avoiding false positives when selecting for jobs having low selection ratio (many candidates and few openings needed to fill).

Other significant correlations involved danger in the work place. Participants reporting having had accidents at work made greater use of the cues presented. Accidents at work (recoded as 1 for no accidents and 0 for having had an accident at work) was significantly correlated to $\mathrm{R}$-square $(\mathrm{r}=.19, \mathrm{p}<.05)$. It was also negatively correlated to decision average $(\mathrm{r}=-.25, \mathrm{p}<.01)$. In fact, participants who indicated they have had an accident at work, had witnessed an accident at work, or worked in a dangerous place were all less likely to pass a candidate in general.

Overall, these results suggest that personality and cognitive complexity may play a very limited role in determining how much relative importance individuals place on job characteristics when making selection decisions. Although the job characteristics affected people's decisions (their likelihood of moving a candidate along the process), their personality and cognitive complexity had little bearing on the decisions made.

In summary, job characteristics influenced how much relative importance decision makers placed on avoiding false positives independently of their personality and cognitive complexity. Moreover, other individual differences such as ethnicity and 
having had an accident at work also had an influence on the importance people placed on the four job characteristics presented in this study and their likelihood to avoid false positives. 


\section{Chapter V}

\section{Discussion}

The focus of this study was to examine if contextual factors affect selection decisions. The hypotheses in these studies were developed because of the notion that individuals do not make selection decisions in a vacuum. That is, other factors can play a role in decisions. A policy-capturing design was created to determine how individuals make selection decisions. Several job characteristics were identified as possible factors which could influence personnel selection decisions. Additionally, the individual differences people bring when making choices was explored.

As anticipated, individuals made decisions differently when presented with candidates for different jobs. The hypotheses related to contextual factors received support in this study. Results showed that in particular, the wage and training requirements of a job impact selection decisions. Respondents were often less likely to move a candidate along the selection process if jobs had either high training requirements or a high salary. Participants were simply more concerned with false positives for these jobs. This is consistent with previous findings about organizations being more cautious when considering jobs requiring more training and having higher pay. Wilk and Capelli (2006) found that when jobs required higher skills, provided more training, and had higher pay, organizations used more selection methods. Additionally, as pay and training/skill requirements increased, organizations consistently relied more on testing methods in the selection process, focusing on methods capturing the applicant's capability to do the work (i.e. work experience and test performance).

A third job characteristic, security concerns, received some support. That is, 
when making selection decisions for jobs involving the security of others (i.e., lifeguard, chemical plant operator), participants showed some restraint, particularly in the SR sample. About $20 \%$ of all respondents considered security concerns as an important job attribute when making decisions ( $25 \%$ of SR sample). The lack of a relationship between jobs involving security concerns and selection decisions may have been a result of the way in which this cue was presented. Unlike the other job characteristics, job security concerns were not explicitly stated (see Appendix B for an example). Instead, security concerns associated with a job were implied in the job descriptions provided to participants. It is possible some participants did not clearly distinguish between high and low levels of this cue.

No evidence was found for the applicant pool/selection ratio of a job. For jobs having many more candidates than needed, it was expected individuals would be more selective and less likely to accept a borderline candidate. Results however, indicate participants cared very little for the remaining number of positions they needed to fill for a job. Whether a job had one or ten vacancies had little impact on the likelihood of participants moving along borderline candidates in the selection process. This finding does not mirror previous research studying the effect faking has on personality tests and its impact on hiring decisions. Previous research has reported that when selection ratios are low (many candidates and few openings), those with an incentive to fake on selection tests (i.e. personality tests), were more likely to be selected (Mueller-Hanson, Heggestad \& Thornton, 2003). In other words, decision makers chose differently when faced with low selection ratios. However, this was not the case in this study. Perhaps a lack of understanding regarding selection ratios affected these results. Participants might not 
have been savvy enough in terms of selection to understand the nuance of making selection decisions in the face of varying selection ratios.

Another purpose of this study was to explore how the individual differences of decision makers affect their decisions. More specifically, I wanted to assess the role of personality and cognitive complexity in risk taking and cue usage during personnel selection. Overall, results showed cognitive complexity did not play a role in how much relative importance decisions makers placed in the job characteristics presented. In fact, results were unexpected. For example, individuals with high cognitive complexity scores, who are presumably able to process information more effectively and are multidimensional in their thinking, made less use of the cues presented.

The literature on cognitive complexity has presented conflicting results regarding its impact on decision-making. Some researchers have found evidence for cognitive complexity improving or enhancing judgments (Spengler \& Strohmer, 1994; Dierdorff \& Rubin, 2007) others have found it to be unrelated (Garb \& Lutz, 2001). Findings in this study seem to support the latter, as cognitive complexity was not a factor influencing decisions. The lack of findings regarding cognitive complexity in this study can be due to the way in which it was measured. The measure of cognitive complexity used in this study may have been inadequate. Although Spengler \& Strohmer (1994) reported high correlations between the reduced $4 \times 6$ matrix used in this study and the more traditional $10 \times 10$, it is possible that this was not a good measure of cognitive complexity.

Like cognitive complexity, personality had almost no relationship with the level of cue usage and overall likelihood of accepting (rejecting) a candidate. Results were not significant when exploring the relationship between personality and decision-making. 
Perhaps using the big five factors was not the best way to explore the role of personality in personnel selection. The use of narrower and more specific facets may have helped uncover any existing relationships between the personality of decision makers and their decisions. For instance, Ashton (1998) argues that too much information is lost using broad factors (i.e., big five), inhibiting the understanding of which narrower facets have the strongest relationship with any criteria of interest. Similarly, the use of broad personality factors may have limit our understanding of what individual variables of decision makers affect personnel decisions, because too much information is lost.

In contrast, other interesting relationships were observed relating to individual differences. Although not predicted by our hypotheses, several demographic variables were related to the job characteristics presented and thus the relative importance individuals placed in them. A particularly surprising finding was the significant and negative correlation between the beta for applicant pool and race/ethnicity. Hispanics placed more relative importance on avoiding false positive errors in this cue across the SR sample. That is, Hispanics were less likely to move along candidates for jobs having low selection ratios (few openings). This finding is surprising because Hispanics do not believe whites and minorities have equal job opportunities. A poll conducted in 2006, found that while a majority of whites (53\%) believe different ethnic groups have equal job opportunities, only $34 \%$ of Hispanics agreed with such statement (Carroll, 2006). Thus, it seems Hispanics would be more likely to pass along candidates and be more inclusive, providing as many candidates as possible with a job opportunity. While it seems intuitive that a minority group would be more inclusive, this was not the case. 
Another surprising and significant finding involved the employment status in the student sample. That is, in the student sample, unemployed participants were less likely to move candidates along for the higher paying jobs. Intuitively, it can be expected for unemployed individuals to be more inclusive and sympathetic when evaluating others. However, this finding was unique to the student sample, which might suggest a couple of things. First, these participants might not be really unemployed, but simply are not working because they are students and are focusing on their education. In other words, they are not looking for work and thus do not behave like unemployed individuals who are indeed looking for work. Alternatively, because they are students, they might feel that borderline candidates should not be selected for higher paying jobs. After all, they are more likely to over value a college education since they are in the process of obtaining one and thus feel only clearly qualified candidates deserve high paying jobs. Future studies should explore possible underlying reasons for these findings.

Other significant relationships were found for age in the SR sample. Age was significantly and positively correlated to R-square. Specifically, it was related to the importance placed in security $(\mathrm{r}=.21, \mathrm{p}<.05)$ and wage $(\mathrm{r}=.28, \mathrm{p}<.01)$. As age increased so did the relative importance placed on these cues when making decisions. Perhaps the experience people acquire with age and thus a greater understanding of how things are related impacts decisions.

Finally, having had an accident or witnessing one at work had an impact on decisions. In the SR sample, individuals who reported having had an accident at work made greater use of the training cue. These participants were less likely to move along candidates for jobs having higher training requirements. In fact, these participants were 
less likely to move anyone along in the process. There was a negative correlation between having had an accident at work and overall decision average. This was also true for individuals that witnessed an accident at work or reported working in a dangerous environment.

The present study made several unique contributions to the existing personnel selection literature. As mentioned before, there is a dearth of research in selection focusing on actual decision-making, although there is a lot of research focusing on performance prediction. Although the literature is rich with knowledge regarding selection tools and predictive studies, research regarding how people actually make decisions is scarce. Because effective employee selection can lead to large gains in productivity, understanding how individuals make hiring decisions has enormous practical implications. The results of this study shows how contextual factors (i.e., job characteristics) can indeed affect someone's willingness to take risk and avoid selection errors. Personnel selection is not merely the result of selection tests. Personnel selection is the results of selection tests interpreted through the lens of contextual factors.

Another contribution was regarding the role of individual differences in selection decisions. This study was unique in that it explored the role of an individual's demographics in making the decisions. Results indicate the context seems to override individual differences. Neither personality nor cognitive complexity made a difference in how the contextual factors affected participants. Moreover, some of the demographic characteristics, such as accidents at work and working in a dangerous environment speak more about the context of the job, not the individual making decisions. That is, where you work, what you experience at work (i.e. accident), and the job for which decisions 
are being made, appear to be more important than the individual differences and biases people bring to personnel selection.

\section{Limitations}

This study has several limitations. Using students and non-personnel decision makers in this study limits the usefulness of the results presented. It cannot be assumed personnel decision makers use the same thought processes when making their decisions. Furthermore, hypothetical selection scenarios were used as participants made simulated, not actual judgments. There simply was no penalty/reward for moving a candidate along (or not) in the process. In other words, there was no penalty for risk aversion/risk taking. There was nothing in this study to motivate participants to either take or avoid a risk. On the other hand, organizations and decision makers face pressure to fill vacancies and deal with real legal and financial consequences, which can influence a risk taking or risk avoidance decision. Although this real pressure is difficult to replicate, a motivation condition can be used in future studies to create a sense of gain or loss from making these simulated judgments. Perhaps a system can be designed were payoffs are provided to participants based on number of projected false positives/negatives from their decisions.

Another limitation involved the use of written job descriptions and candidates. These are clearly not as realistic as actual job openings and candidates. For example, organizations and decision makers often need to fill vacancies due to productivity loss and internal demands. Future researchers should attempt to create high/low pressure situations to see how it affects decision makers. Other job characteristics should also be examined as only four were explored in this study. More characteristics such as size of 
organization, time of current vacancy, turnover patterns can impact decisions and thus should be explored.

Finally, individual differences should be operationalized differently, including additional variables (i.e. leadership style), more cognitive ability variables and narrower personality facets. Although cognitive complexity and Bieri's repertory grid technique have been used extensively, some researchers have questioned them as a construct and as a measure of cognitive complexity respectively. Future research should consider both other measures of cognitive complexity and other cognitive constructs to better understand their role in personnel decision-making.

A particularly interesting approach could be to explore the role of personality in selection decisions using personality profile types. That is, using combinations of personality factors/facets to explore the relationship between the individual characteristics of decision makers and their decisions. For example, a higher order factor such as plasticity which is composed of openness to experience and extraversion can be explored. Perhaps combinations such as openness, agreeableness and extraversion could be the profile of a perceptive and team oriented person. This person in turn might make decisions differently than an unobservant individualistic person. Although personality was not found to be a good predictor in this study, it may be possible to gain a better understanding if explored differently.

Finally, this study revealed individual demographic variables (i.e. accidents at work, employment status) impacting the significance decision makers placed on the cues presented, thus impacting their decisions. Further research needs to uncover additional individual demographic differences (i.e. experience in selection and legal matters) and 
their possible reasons for influencing decisions. Research investigating how these other factors and individual differences variables relate to personnel decisions would benefit the selection literature.

\section{Implications for Organizations}

Understanding the most effective selection methods is important in selecting top candidates with maximum utility. However, it is also important to understand how internal/external motivational and cognitive factors affect selectors in hiring situations. The results of this study confirm the hypotheses that job factors (i.e., training, wage) influence the risk people are willing to take when selecting candidates. These results emphasize the need for further examination into how individuals make selection decisions. This knowledge can enhance an organization's ability to adapt to external needs and overcome barriers.

For example, an organization may need to pay attention to particular jobs where decision makers are reluctant to make mistakes. The organization may be eliminating possible good candidates because of the unwillingness of decision makers to take risks (and reduce false positives). Additional training, more specific selection tools and a different set of rules can be given to decision makers when filling these positions to facilitate the process. Alternatively, an organization may warn its decision makers to remain highly selective even if the job appears to be simple, has a low salary, or does not involve the safety of others. However, without knowing which characteristics are influencing decision makers, it is hard to form a strategy. Moreover, understanding which factors lead to lenient decisions may be of great importance for an organization. In this case, if an organization realizes which factors affect decision makers or under which 
circumstances they are more likely to take risks (and increase false positives), the organization can take preventive measures (i.e. training). Another implication that can be drawn from these results is regarding training. Managers need to become more aware of how they make selection decisions and the hiring policies they use. Perhaps a thorough system of providing feedback to companies regarding the policies their managers use in selection can be beneficial.

\section{Conclusion}

Most of the academic literature in selection has focused on identifying the characteristics and methods needed to identify the best candidate for a given job. However, as discussed in this study, a number of internal and external factors can affect

decision makers. These factors, whether individual, organizational or societal need to be understood in order to minimize their possible bias and negative impact on selection decisions. It is my understanding that this study is the first to investigate the role these factors play in personnel decision-making. Therefore, I hope it stimulates further research to help us better understand decisions and not just selection methods.

In summary, by understanding the specific elements of the decision making process, organizations can adopt a selection process better suited to meet their needs. Understand when training is needed, the advising tasks associated with various approaches as needed. Based on this study, we underline the need for a better understanding of the decision making process as a whole, not just the tools used in making decisions. 
Table 1

T-test Comparisons for Both Samples for all Relevant Independent and Demographic

Variables

\begin{tabular}{lcccc}
\hline Variable & $\begin{array}{c}\text { Student Sample } \\
(\mathrm{N}=102)\end{array}$ & $\begin{array}{c}\text { StudyResponse Sample } \\
(\mathrm{N}=143)\end{array}$ & t-value & $\mathrm{d}$ \\
\hline Openness & $3.94(.48)$ & $3.70(.59)$ & $3.62^{* *}$ & .25 \\
Extraversion & $3.26(.75)$ & $3.10(.78)$ & 1.57 & .16 \\
Agreeableness & $3.77(.59)$ & $3.87(.61)$ & -1.25 & -.10 \\
Conscientiousness & $3.70(.63)$ & $3.64(.71)$ & 1.87 & .05 \\
Neuroticism & $3.07(.74)$ & $2.95(.82)$ & 1.19 & .12 \\
Cognitive Complexity & $42.02(6.96)$ & $40.58(8.06)$ & 1.45 & 1.44 \\
Age & $22.06(4.48)$ & $43.90(12.95)$ & $-18.59^{* *}$ & -21.84 \\
Gender & $.79(.41)$ & $.69(.47)$ & $1.94^{*}$ & .11 \\
Race & $.80(.40)$ & $.13(.34)$ & $13.78^{* *}$ & .67 \\
Job Status & $.35(.48)$ & $.39(.49)$ & -.55 & -.03 \\
Number of Interviews & $3.80(3.42)$ & $9.77(18.27)$ & $-3.79^{* *}$ & -5.97 \\
Involvement in Selection & $.57(.50)$ & $.44(.50)$ & $1.94 *$ & .13 \\
Accident at Work & $.97(.17)$ & $.88(32)$ & $2.80^{* *}$ & .09 \\
Witnessing accident at Work & $.83(.37)$ & $.76(.43)$ & 1.51 & .08 \\
Work Dangerous Place & $.81(.39)$ & $.59(.49)$ & $3.88^{* *}$ & .22 \\
\hline
\end{tabular}

* $\mathrm{t}$ significant at $\mathrm{p}<.05$.

$* *$ t significant at $\mathrm{p}<.01$.

Gender (recoded 0 for male and 1 for female)

Race (recoded 0 for non-Hispanic and 1 for Hispanic)

Job Status (recoded as 0 for employed and 1 for unemployed)

Previous Involvement in Selection (recoded as 0 for yes and 1 for no)

Accident at Work (recoded as 0 for yes and 1 for no)

Witnessing Accident at Work (recoded as 0 for yes and 1 for no)

Work Dangerous Place (recoded as 0 for yes and 1 for no) 
Table 2

Multiple Regression Analysis of the Relationship between Job Characteristics and Decision Average across All Job Profiles for Student Sample

\begin{tabular}{lcccc}
\hline & $\beta$ & $b$ & $S E$ & $t$ \\
\hline Applicant Pool & -.03 & -.06 & .25 & -.24 \\
Security Concerns & .19 & .34 & .25 & 1.351 \\
Training/Complexity & $.60^{* *}$ & 1.10 & .25 & 4.387 \\
Wage & $.49^{* *}$ & .90 & .25 & 3.604 \\
& & & & \\
$R^{2}$ & .73 & & & \\
$F$ & $9.870^{* *}$ & & & \\
\hline
\end{tabular}

Decision average is the average of all participants for each job profile

* significant at $\mathrm{p}<.05$

** significant at $\mathrm{p}<.01$

Table 3

Multiple Regression Analysis of the Relationship between Job Characteristics and Decision Average across All Job Profiles for SR Sample

\begin{tabular}{lcclc}
\hline & $\beta$ & $b$ & $S E$ & $t$ \\
\hline & & & & \\
Applicant Pool & -.04 & -.07 & .20 & -.323 \\
Security Concerns & $.34^{*}$ & .54 & .20 & 2.680 \\
Training/Complexity & $.52^{* *}$ & .83 & .20 & 4.119 \\
Wage & $.53^{* *}$ & .84 & .20 & 4.168 \\
& & & & \\
$R^{2}$ & .77 & & & \\
$F$ & $12.246^{* *}$ & & & \\
\hline
\end{tabular}

Decision average is the average of all participants for each job profile

* significant at $\mathrm{p}<.05$

** significant at $\mathrm{p}<.01$ 
Table 4

Mean Standardized Regression Coefficients by Job Characteristic for Student Sample

\begin{tabular}{lcccc}
\hline & Applicant Pool & Security Concerns & Training Needed & Wage \\
\hline & & & & \\
M & -.01 & .13 & .39 & .32 \\
SD & .18 & .21 & .27 & .26 \\
Range & -.41 to .49 & -.72 to .71 & -.60 to .95 & -.90 to .94 \\
\hline
\end{tabular}

Table 5

Mean Standardized Regression Coefficients by Job Characteristic for Study Response Sample

\begin{tabular}{lcccc}
\hline & Applicant Pool & Security Concerns & Training Needed & Wage \\
\hline & & & & \\
M & .00 & .18 & .27 & .27 \\
SD & .17 & .23 & .28 & .31 \\
Range & -.78 to .36 & -.37 to .79 & -.50 to .93 & -.94 to .88 \\
\hline
\end{tabular}


Table 6

Number of Significant $\beta$ s for Student Sample

\begin{tabular}{lcccc}
\hline & $\begin{array}{c}\text { Applicant } \\
\text { Pool }\end{array}$ & Security Concerns & Training/Complexity & Wage \\
\hline $\mathrm{N}$ & 102 & 102 & 102 & \\
$\#$ of Sig $\beta \mathrm{s}$ & 1 & 13 & 53 & 102 \\
$\%$ of $\operatorname{sig} \beta \mathrm{s}$ & $1 \%$ & $13 \%$ & $52 \%$ & 49 \\
\hline
\end{tabular}

Table 7

Number of Significant $\beta$ s for Study Response Sample

\begin{tabular}{lcccc}
\hline & $\begin{array}{c}\text { Applicant } \\
\text { Pool }\end{array}$ & Security Concerns & Training/Complexity & Wage \\
\hline $\mathrm{N}$ & 143 & 143 & 143 & \\
\# of Sig $\beta \mathrm{s}$ & 3 & 36 & 58 & 143 \\
$\%$ of $\operatorname{sig} \beta \mathrm{s}$ & $2 \%$ & $25 \%$ & $41 \%$ & 64 \\
\hline
\end{tabular}


Table 8

Meta-Analysis of the Standardized beta Coefficients for Each Job Characteristic

\begin{tabular}{lcccccc}
\hline Job Characteristic & $\mathrm{K}$ & $\mathrm{N}$ & $\mathrm{r}$ & $\mathrm{SD}_{\mathrm{r}}$ & $\mathrm{SE}_{\mathrm{SD}}$ & $\mathrm{RES}_{\mathrm{SD}}$ \\
\hline Student Sample & & & & & & \\
Applicant Pool & 102 & 2040 & -.01 & .18 & .2294 & 0 \\
Security Concerns & 102 & 2040 & .13 & .21 & .2255 & 0 \\
Training/Complexity & 102 & 2040 & .39 & .27 & .1945 & .0755 \\
Wage & 102 & 2040 & .32 & .26 & .2059 & .0541 \\
& & & & & & \\
Study Response & & & & & & \\
Sample & 143 & 2860 & .00 & .17 & .2294 & .2220 \\
Applicant Pool & 143 & 2860 & .18 & .23 & .227 & .0080 \\
Security Concerns & 143 & 2860 & .27 & .28 & .2127 & .0673 \\
Training/Complexity & 143 & 2860 & .27 & .31 & .2127 & .0973 \\
Wage & & & & & & \\
& & & & &
\end{tabular}


Table 9

95\% CI for job characteristics around standardized betas using SE for Student Sample 95\% CI

\begin{tabular}{lcccc} 
Job Characteristics & $\beta$ & $S E$ & lower & upper \\
\hline Applicant Pool & -.013 & .018 & -.048 & .022 \\
Security Concerns & .128 & .021 & .086 & .170 \\
Training/Complexity & .387 & .026 & .334 & .439 \\
Wage & .323 & .026 & .271 & .375 \\
& & & & \\
\hline
\end{tabular}

Table 10

95\% CI for job characteristics around standardized betas using SE for SR Sample

\begin{tabular}{lcccc}
\hline & & \multicolumn{3}{c}{$95 \%$ CI } \\
Job Characteristics & $\beta$ & $S E$ & lower & upper \\
\hline Applicant Pool & .002 & .014 & -.026 & .030 \\
Security Concerns & .178 & .019 & .140 & .216 \\
Training/Complexity & .274 & .023 & .227 & .320 \\
Wage & .272 & .026 & .221 & .324 \\
& & & & \\
\hline
\end{tabular}


Table 11

Means, Standard Deviations, and Intercorrelations for Student Sample

\begin{tabular}{|c|c|c|c|c|c|c|c|c|c|c|c|c|c|}
\hline Variable & Mean & $\mathrm{SD}$ & 1 & 2 & 3 & 4 & 5 & 6 & 7 & 8 & 9 & 10 & 11 \\
\hline 1. Openness & 3.94 & .48 & - & & & & & & & & & & \\
\hline 2. Extraversion & 3.26 & .75 & $.38 * *$ & - & & & & & & & & & \\
\hline 3. Agreeableness & 3.77 & .59 & $.42 * *$ & $.46^{* *}$ & - & & & & & & & & \\
\hline 4. Conscientiousness & 3.70 & .63 & $.20 *$ & $.21^{*}$ & $.36 * *$ & - & & & & & & & \\
\hline 5. Neuroticism & 3.07 & .74 & $-.19 *$ & $-.37 * *$ & $-.41 * *$ & $-.36^{* *}$ & - & & & & & & \\
\hline 6. Cognitive Complexity & 42.02 & 6.96 & -.06 & -.11 & $-.28 * *$ & -.07 & $.33 * *$ & - & & & & & \\
\hline 7. ßapplicant & -.013 & .18 & .05 & .05 & .01 & .06 & .00 & .01 & - & & & & \\
\hline 9. $\beta$ training & .387 & .27 & .01 & -.08 & -.02 & -.08 & .09 & .06 & -.03 & $.29 * *$ & - & & \\
\hline 10. $\beta$ wage & .323 & .26 & -.16 & -.04 & -.03 & .03 & -.01 & .11 & -.06 & -.01 & .02 & - & \\
\hline 11. $\mathrm{R}^{2}$ & .529 & .19 & -.01 & .03 & .08 & -.05 & .04 & -.03 & .05 & $.27 * *$ & $.49 * *$ & $.24 *$ & - \\
\hline 12. Decision Average & 3.81 & .46 & -.02 & -.08 & .07 & .14 & -.02 & .04 & .07 & -.01 & .18 & .03 & .14 \\
\hline
\end{tabular}

* Correlation is significant at the .05 level (1-tailed).

** Correlation is significant at the .01 level (1-tailed).

Note. Variables 7-10 represent the weight placed on each job characteristic cue. 
Table 12

Means, Standard Deviations, and Intercorrelations for StudyResponse Sample

\begin{tabular}{|c|c|c|c|c|c|c|c|c|c|c|c|c|c|}
\hline Variable & Mean & $\mathrm{SD}$ & 1 & 2 & 3 & 4 & 5 & 6 & 7 & 8 & 9 & 10 & 11 \\
\hline 1. Openness & 3.70 & .59 & - & & & & & & & & & & \\
\hline 2. Extraversion & 3.10 & .78 & $.41 * *$ & - & & & & & & & & & \\
\hline 3. Agreeableness & 3.87 & .61 & $.36^{* *}$ & $.40 * *$ & - & & & & & & & & \\
\hline 4. Conscientiousness & 3.64 & .71 & $.38 * *$ & $.35 * *$ & $.34 * *$ & - & & & & & & & \\
\hline 5. Neuroticism & 2.95 & .82 & $-.23 * *$ & $-.24 * *$ & -.11 & $-.37 * *$ & - & & & & & & \\
\hline 6. Cognitive Complexity & 40.58 & 8.06 & -.05 & $-.24 * *$ & $-.17 *$ & .01 & .14 & - & & & & & \\
\hline 7. Bapplicant & .002 & .17 & $-.17 *$ & -.10 & $-.17 *$ & -.07 & .06 & .03 & - & & & & \\
\hline 8. $\beta$ security & .178 & .23 & $.20 *$ & .15 & $.24 * *$ & .07 & $-.16^{*}$ & -.16 & .01 & - & & & \\
\hline 9. $\beta$ training & .274 & .28 & .11 & .05 & .10 & .06 & -.04 & .05 & .04 & $.28 * *$ & - & & \\
\hline 10. $\beta$ wage & .272 & .32 & $.22 * *$ & .13 & $.19^{*}$ & .09 & -.09 & .08 & -.04 & $.24 * *$ & $.28 * *$ & - & \\
\hline 11. $\mathrm{R}^{2}$ & .471 & .23 & .11 & .14 & $.18^{*}$ & .02 & -.11 & $-.20 * *$ & -.11 & $.46^{* *}$ & $.58 * *$ & $.42 * *$ & - \\
\hline 12. Decision Average & 3.77 & .69 & .01 & .02 & -.03 & .03 & -.04 & .04 & .10 & $-.24 * *$ & -.10 & $-.23 * *$ & $-.30 * *$ \\
\hline
\end{tabular}

* Correlation is significant at the .05 level (1-tailed).

** Correlation is significant at the .01 level (1-tailed).

Note. Variables 7-10 represent the weight placed on each job characteristic cue. 
Table 13

Multiple Regression Analysis of the Relationship between Individual Differences and $R^{2}$ for Student Sample $(n=102)$

\begin{tabular}{lcccc}
\hline & $\beta$ & $b$ & $S E$ & $t$ \\
\hline Cognitive Complexity & -.02 & .00 & & \\
Openness & -.05 & -.02 & .00 & -.140 \\
Conscientiousness & -.07 & -.02 &. .47 & -.443 \\
Extraversion & .03 & .01 & .35 & -.623 \\
Neuroticism & .07 & .02 & .31 & .215 \\
Agreeableness & .13 & .04 & .43 & .575 \\
& & & .04 & 1.022 \\
$R^{2}$ & .02 & & & \\
$F$ & .287 & & & \\
\hline
\end{tabular}

$*$ significant at $\mathrm{p}<.05$

$* *$ significant at $\mathrm{p}<.01$

Table 14

Multiple Regression Analysis of the Relationship between Job Characteristics and $R^{2}$ for $S R$ Sample $(n=143)$

\begin{tabular}{lcccc}
\hline & $\beta$ & $b$ & $S E$ & $t$ \\
\hline Cognitive Complexity & -.15 & -.00 & .00 & -1.687 \\
Openness & .04 & .02 & .04 & .435 \\
Conscientiousness & -.09 & -.03 & .03 & -.905 \\
Extraversion & .04 & .01 & .03 & .392 \\
Neuroticism & -.09 & -.02 & .03 & -.923 \\
Agreeableness & .14 & .05 & .04 & 1.467 \\
$R^{2}$ & & & & \\
$F$ & .07 & & & \\
\hline
\end{tabular}

$*$ significant at $\mathrm{p}<.05$

$* *$ significant at $\mathrm{p}<.01$ 
Table 15

Multiple Regression Analysis of the Relationship between Individual Differences and Decision Average for Student Sample $(n=102)$

\begin{tabular}{lcccc}
\hline & $\beta$ & $b$ & $S E$ & $t$ \\
\hline Cognitive Complexity & .07 & .00 & .01 & .601 \\
Openness & -.04 & -.04 & .11 & -.322 \\
Conscientiousness & .14 & .10 & .08 & 1.265 \\
Extraversion & -.14 & -.08 & .07 & -1.142 \\
Neuroticism & -.01 & -.01 & .08 & -.076 \\
Agreeableness & .11 & .08 & .10 & .823 \\
$R^{2}$ & & & & \\
$F$ & .04 & & & \\
\hline
\end{tabular}

Decision Average is the overall decision average of each participant across all jobs.

* significant at $\mathrm{p}<.05$

** significant at $\mathrm{p}<.01$

Table 16

Multiple Regression Analysis of the Relationship between Job Characteristics and Decision Average for SR Sample $(n=143)$

\begin{tabular}{lllll}
\hline & $\beta$ & $b$ & $S E$ & $t$ \\
\hline Cognitive Complexity & .04 & .00 & .01 & .443 \\
Openness & .01 & .01 & .12 & .095 \\
Conscientiousness & .03 & .03 & .10 & .251 \\
Extraversion & .03 & .03 & .09 & .275 \\
Neuroticism & -.04 & -.04 & .08 & -.467 \\
Agreeableness & -.05 & -.06 & .11 & -.540 \\
$R^{2}$ & & & & \\
$F$ & .01 & & & \\
\hline
\end{tabular}

Decision Average is the overall decision average of each participant across all jobs.

* significant at $\mathrm{p}<.05$

$* *$ significant at $\mathrm{p}<.01$ 
Table 17

Multiple Regression Analysis of the Relationship between Individual Differences and beta weights of the job characteristics for Student Sample $(N=102)$

\begin{tabular}{lccccccccc}
\hline & \multicolumn{4}{c}{ Number of Applicants } & \multicolumn{4}{c}{ Security Concerns } \\
\cline { 2 - 10 } & $\beta$ & $b$ & $S E$ & $t$ & & $\beta$ & $b$ & $S E$ & $t$ \\
\hline \multirow{2}{*}{ Cognitive Complexity } & .00 & 2.71 & .00 & .010 & -.05 & -.00 & .00 & -.417 \\
Openness & .04 & .02 & .04 & .378 & .06 & .03 & .05 & .536 \\
Conscientiousness & .07 & .02 & .03 & .597 & .02 & .01 & .04 & .168 \\
Extraversion & .06 & .01 & .03 & .469 & -.08 & -.02 & .04 & -.689 \\
Neuroticism & .04 & .01 & .03 & .301 & .06 & .02 & .04 & .503 \\
Agreeableness & -.05 & -.01 & .04 & -.360 & -.03 & -.01 & .05 & -.198 \\
& & & & & & & & \\
$R^{2}$ & .01 & & & & .01 & & & \\
$F$ & .144 & & & & .224 & & & \\
\hline
\end{tabular}

* significant at $\mathrm{p}<.05$

** significant at $\mathrm{p}<.01$

\begin{tabular}{lccccccccc}
\hline & \multicolumn{4}{c}{ Wage } & \multicolumn{4}{c}{ Training Requirements } \\
\cline { 2 - 10 } & $\beta$ & $b$ & $S E$ & $t$ & & $\beta$ & $b$ & $S E$ & $t$ \\
\hline \multirow{2}{*}{ Cognitive Complexity } & .14 & .01 & .00 & 1.26 & .05 & .00 & .00 & .474 \\
Openness & -.19 & -.10 & .06 & -1.64 & .05 & .03 & .07 & .414 \\
Conscientiousness & .04 & .02 & .05 & .343 & -.07 & -.03 & .05 & -.658 \\
Extraversion & .00 & .00 & .04 & -.005 & -.09 & -.03 & .04 & -.753 \\
Neuroticism & -.05 & -.02 & .04 & -.444 & .05 & .02 & .04 & .387 \\
Agreeableness & .05 & .02 & .06 & .412 & .07 & .03 & .06 & .515 \\
& & & & & & & & \\
$R^{2}$ & .05 & & & & .02 & & & \\
$F$ & .741 & & & & .328 & & & \\
\hline
\end{tabular}

* significant at $\mathrm{p}<.05$

$* *$ significant at $\mathrm{p}<.01$ 
Table 18

Multiple Regression Analysis of the Relationship between Individual Differences and beta weights of the job characteristics for SR Sample $(N=143)$

\begin{tabular}{lccccccccc}
\hline & \multicolumn{4}{c}{ Number of Applicants } & \multicolumn{3}{c}{ Security Concerns } \\
\cline { 2 - 10 } & $\beta$ & $b$ & $S E$ & $t$ & & $\beta$ & $b$ & $S E$ & $t$ \\
\hline \multirow{2}{*}{ Cognitive Complexity } & -.01 & .00 & .00 & -.093 & -.10 & -.00 & .00 & -1.187 \\
Openness & -.12 & -.03 & .03 & -1.168 & .12 & .05 & .04 & 1.263 \\
Conscientiousness & .04 & .01 & .02 & .409 & -.09 & -.03 & .03 & -.926 \\
Extraversion & -.01 & -.00 & .02 & -.088 & -.01 & -.00 & .03 & -.145 \\
Neuroticism & .02 & .00 & .02 & .195 & -.14 & -.04 & .03 & -1.594 \\
Agreeableness & -.14 & -.04 & .03 & -1.420 & & .19 & .07 & .04 & $2.044^{*}$ \\
& & & & & & & & \\
$R^{2}$ & .04 & & & & .10 & & & \\
$F$ & .952 & & & & 2.509 & & & \\
\hline
\end{tabular}

* significant at $\mathrm{p}<.05$

** significant at $\mathrm{p}<.01$

\begin{tabular}{lccccccccc}
\hline & \multicolumn{4}{c}{ Wage } & \multicolumn{4}{c}{ Training Requirements } \\
\cline { 2 - 10 } & $\beta$ & $b$ & $S E$ & $t$ & $\beta$ & $b$ & $S E$ & $t$ \\
\hline \multirow{2}{*}{ Cognitive Complexity } & .14 & .00 & .00 & 1.573 & .07 & .00 & .00 & .755 \\
Openness & .17 & .09 & .05 & 1.792 & .08 & .03 & .05 & .725 \\
Conscientiousness & -.06 & -.03 & .04 & -.636 & .00 & .00 & .04 & -.007 \\
Extraversion & .04 & .02 & .04 & .444 & -.00 & .00 & .04 & -.022 \\
Neuroticism & -.07 & -.03 & .04 & -.736 & -.03 & -.01 & .03 & -.314 \\
Agreeableness & .15 & .08 & .05 & 1.583 & .08 & .04 & .05 & .775 \\
& & & & & & & & & \\
$R^{2}$ & .09 & & & & .02 & & & \\
$F$ & 2.107 & & & & .432 & & & \\
\hline
\end{tabular}

* significant at $\mathrm{p}<.05$

$* *$ significant at $\mathrm{p}<.01$ 


\section{References}

Ackerman, P. L., \& Heggestad, E. D. (1997). Intelligence, personality, and interests: Evidence for overlapping traits. Psychological Bulletin, 121, 219-245.

Anderson, N., Born, M. and Cunningham-Snell, N. (2001) Recruitment and Selection: Applicant perspectives and outcomes. In: Anderson, N., Ones, D.S., Sinangil, H.K. and Viswesvaran, C. (Eds), Handbook of Industrial, Work \& Organizational Psychology. Vol. 1: Personnel psychology (pp. 200-218). London, UK: Sage.

Anderson, N. and Witvliet, C. (2008). Fairness reactions to personnel selection methods: An international comparison between the Netherlands, the United States, France, Spain, Portugal, and Singapore. International Journal of Selection and Assessment, 16, 1-13.

Arvey, R. D. (1979). Fairness in selecting employees. Massachusetts: Addison-Wesley Pub. Co.

Barrick, M. R., \& Mount, M. K. (1991). The big five personality dimensions and job performance: A meta-analysis. Personnel Psychology, 44, 1-26.

Barrick, M. R. \& Zimmerman, R. D. (2005). Reducing voluntary, avoidable turnover through selection. Journal of Applied Psychology, 90(1), 159-166.

Bieri J, Atkins A L, Briar S, Leaman R L, Miller H \& Tripodi T. (1966). Clinical and social judgment: the discrimination of behavioral information. New York: Wiley.

Born, M.Ph., \& Scholarios, D. (2005). Decision making in selection. In A.V.A.M. Evers, O. Smit-Voskuyl, and N. Anderson (Eds.). The Blackwell Handbook of Personnel Selection . (pp. 267-290). Wiley-Blackwell.

Briner, Rob B. \& Denise M. Rousseau (2011). Evidence-based I-O psychology: Not there yet. Industrial \& Organizational Psychology, 4, p. 3-22

Brtek, M. D., \& Motowidlo, S. J. (2002). Effects of procedure and outcome accountability on interview validity. Journal of Applied Psychology, 87(1), 185-191.

Busenitz, L.W. (1999). Entrepreneurial risk and strategic decision making: It's a matter of perspective. Journal of Applied Behavioral Science, 35(3), 325-340.

Cabrera, E.F., \& Raju, N.S. (2001). Utility Analysis: Current trends and future directions. International Journal of Selection and Assessment, 9, 92-102.

Carlson, K.D. \& Connerley M.L. (2003). The Staffing Cycles Framework: Viewing Staffing as a System of Decision Events, Journal of Management, 29(1), 51-78.

Carroll, J. (2006). Whites, minorities differ in views of economic opportunities in U.S. Retrieved from http://www.gallup.com/poll/23617/whites-minorities-differ-views-economicopportunities-us.aspx 
Cascio, W. F. (1998). Decision making for selection. In Applied psychology in human resource management (5th edition). Upper Saddle River, NJ: Prentice Hall.

Ceci, S. J., \&Liker, J. (1986). A day at the races: IQ, expertise, and cognitive complexity. Journal of Experimental Psychology: General, 115, 255-266.

Dalton, M., \& Wilson, M. (2000). The relationship of the five-factor model of personality to job performance for a group of Middle Eastern expatriate managers. Journal of CrossCultural Psychology, 31, 250-258.

Dipboye, R. L.(1982). Self-fulfilling prophecies in the selection recruitment interview. Academy of Management Review, 7. 579-587.

Dollinger, M.J. (1984). Environmental boundary spanning and information processing effects on organizational performance. Academy of Management Journal, 27(2), 351-368.

Dierdorff, E. C. \& Rubin, R. S. (2007). Carelessness and discriminability in work role requirement judgments: Influences of role ambiguity and cognitive complexity. Personnel Psychology, 60, 597-625.

Dunn, W. S., Mount, M. K., Barrick, M. R., \& Ones, D. S. (1995). Relative importance of personality and general mental ability in managers' judgments of applicant qualifications. Journal of Applied Psychology, 80, 500-509.

Frank, L., \& Hackman, R. (1975). Effects of interviewer-interviewee similarity on interviewer objectivity in college admissions interviews. Journal of Applied Psychology, 60(3), 356360.

Ghiselli, E. E. (1973), The validity of aptitude tests in personnel selection. Personnel Psychology, 26, 461-477.

Goodwin, V. L. \& Ziegler, L. (1998). A test of relationships in a model of organizational cognitive complexity. Journal of Organizational Behavior, 19, 371-386.

Goldberg, L. R. (1999). A broad-bandwidth, public domain, personality inventory measuring the lower-level facets of several five-factor models. In I. Mervielde, I. Deary, F. De Fruyt, \& F. Ostendorf (Eds.), Personality Psychology in Europe, Vol. 7 (pp. 7-28). Tilburg, The Netherlands: Tilburg University Press. Obtained through website http://ipip.ori.org/ipip/.

Gottfredson, L. S. (1997). Mainstream science on intelligence: An editorial with 52 signatories, history, and bibliography. Intelligence, 24(1), 13-23.

Garb, H.N., \& Lutz, C.J. (2001). Cognitive complexity and the validity of clinicians' judgments. Assessment, 8, 111-115. 
Hausknecht, J. P., Day, D. V. \& Thomas, S. C. (2004). Applicant reactions to selection procedures: An updated model and meta-analysis. Personnel Psychology, 57, 639-683.

Hazer, J. T., \& Highhouse, S. (1997). Factors influencing managers' reactions to utility analysis: Effects of Sdy Method, information frame, and focal intervention. Journal of Applied Psychology, 82, 104-112.

Hooijberg, R., Hunt, J. G., \& Dodge, G. E. (1997). Leadership complexity and development of the Leaderplex Model. Journal of Management, 23(3), 375-408.

Hunter, J. E., \& Hunter, R. F. (1984). Validity and utility of alternative predictors of job performance. Psychological Bulletin, 96, 72-98.

Hunter, J., E., \& Schmidt, F., L. (1990). Dichotomization of continuous variables: The implications for meta-analysis. Journal of Applied Psychology, 75(3), 334-349.

Hunter, J. E., Schmidt, F. L., \& Judiesch, M. K. (1990). Individual differences in output variability as a function of job complexity. Journal of Applied Psychology, 75, 28-42.

International Personality Item Pool (2001). A Scientific Collaboratory for the Development of Advanced Measures of Personality Traits and Other Individual Differences (http://ipip.ori.org/). Internet Web Site.

Johnson, J. W. (2001). The relative importance of task and contextual performance dimensions to supervisor judgments of overall performance. Journal of Applied Psychology, 86, 984996.

Judge, T. A., \& Bono, J. E. (2000). Five-factor model of personality and transformational leadership. Journal of Applied Psychology, 85, 751-765.

Kahneman, D.; Tversky, A. (1979). Prospect theory: An analysis of decisions under risk. Econometrica 47 (2), 263-291.

Kaplan, R. M. and Saccuzzo, D. P. (1997). Psychological testing: Principles, applications, and issues (4th ed.). California: Brooks/Cole.

Klehe, U.-C. (2004). Choosing how to choose: Institutional pressures affecting the adoption of personnel selection procedures. International Journal of Selection and Assessment, 12, $315-330$.

Kline, T. J. B., \& Sulsky, L. M. (1995). A policy-capturing approach to individual decision-making: A demonstration using professors' judgments of acceptability of psychology graduate school applicants. Canadian Journal of Behavioural Science, 27, 393-404. 
Kowert, Paul A. \& Margaret G. Hermann. (1997). Who takes risks? Daring and caution in foreign policy making. Journal of Conflict Resolution 41(5), 611-637.

Lahiri, Somnath, Pérez-Nordtvedt, Liliana \& Renn, Robert W. (2008). Will the new competitive landscape cause your firm's decline? It depends on your mindset, Business Horizons, 51, issue 4 , p. 311-320.

Larson, L. M., Rottinghaus, P. J., \& Borgen, F. H. (2002). Meta-analyses of big six interests and big five personality factors. Journal of Vocational Behavior, 61, 217-239.

Latham, G., \& Whyte, G. (1994). The futility of utility analysis. Personnel Psychology, 47, 3146.

Leonard, R. (1976). Cognitive complexity and the similarity-attraction paradigm. Journal of Research in Personality, 10, 83-88.

Lin, T., Dobbins, G., \& Farh, J. (1992). A field study of race and age similarity effect on interview ratings in conventional and situational interview. Journal of Applied Psychology, 77(3), 363-371.

Macan, T. H., \& Foster, L. (2004). Managers' reactions to utility analysis and perceptions of what influences their decisions. Journal of Business and Psychology, 19, 241-253.

Manshor A. T., Jusoh M., \& Simun M. (2003). Diversity factors and preferential treatments in selecting employees. Journal of Management Development, 22(7), 643-656.

McClelland, D.C. \& Boyatzis, R.E. (1982). Leadership motive pattern and long term success in management. Journal of Applied Psychology, 67(9), 737-743.

Moy J. W. \& Lam K. F. (2004). Selection criteria and the impact of personality on getting hired. Personnel Review, 33(5), 521-535.

Mueller-Hanson, R., Heggestad, E. D., \& Thornton, G. C. (2003). Faking and selection: Considering the use of personality from select-in and select-out perspectives. Journal of Applied Psychology, 88(2), 348-355.

Nicholson, Nigel, Mark Fenton-O'Creevy, Emma Soane, \& Paul William. (2004). Risk Propensity and Personality. Retrieved from http://facultyresearch.london.edu/docs /risk.ps.pdf.

Ones, D. S., Viswesvaran, C., \& Schmidt, F. L. (1993). Meta-analysis of integrity test validities. Journal of Applied Psychology, 78, 679-703.

Ones, D. S., \& Viswesvaran, C. (1997). Personality determinants in the prediction of aspects of expatriate job success. In D. M. Saunders (Series Ed.) \& Z. Aycan (Vol. Ed.), New approaches to employee management: Vol. 4. Expatriate management: Theory and research (pp. 63-92). Greenwich, CT: JAI. 
Ones, D. S., \& Viswesvaran, C. (1999). Relative importance of personality dimensions for expatriate selection: A policy capturing study. Human Performance, 12, 275-294.

Palich, L. E. \& Bagby, D. R. (1995). Using cognitive theory to explain entrepreneurial risktaking: Challenging conventional wisdom. Journal of Business Venturing, 10(6), 425438.

Ployhart, R. E., Schneider, B., \& Schmitt, N. (2006). Staffing organizations: Contemporary practice and theory. Mahwah, N.J: Lawrence Erlbaum Associates.

Rand, T. M. \& Wexley, K.N. (1975). Demonstrations of the effect 'similar to me' in simulated employment interviews. Psychological Reports, 36, 535-544.

Ryan, A \& Tippins, N. (2004). Attracting and selecting: What psychological research tells us? Human Resource Management, 43 (4), 305-318.

Ryan, A. M., McFarland, L., Baron, H., \& Page, R. (1999). An international look at selection practices: Nation and culture as explanations for variability in practice. Personnel Psychology, 52, 359-391.

Rynes, S. L., Colbert, A. E., \& Brown, K. G. 2002. HR professionals' beliefs about effective human resource practitioners and academics. Academy of Management Journal, 44(2), 340-355.

Rynes, S., Brown, K \& Colbert, A. (2002). Seven common misconceptions about human resource practices: Research findings versus practitioner beliefs. Academy of Management Executive, Vol. 16, No. 3, pp. 92-103.

Salgado, J. F. (1997). The factor model of personality and job performance in the European community. Journal of Applied Psychology, 82, 30-43.

Salgado, J.F., Viswesvaran, C., \& Ones, D.S. (2001). Predictors used for personnel selection: An overview of constructs, methods and techniques. In N. Anderson, D.S. Ones, H.K. Sinangil, \& C. Viswesvaran (Eds.), Handbook of industrial, work and organizational psychology: Vol. 1. Personnel Psychology (pp. 165-199). London: Sage.

Salgado, J.F. \& Anderson, N. (2002). Cognitive and GMA testing in the European community: Issues and evidence. Human Performance, 15, 75-96

Schmidt, F. L. \& Hunter, J. E. (1998). The Validity and Utility of Selection Methods in Personnel Psychology. Practical and Theoretical Implications of 85 Years of Research Findings. Psychological Bulletin, 124(2), 262-274. 
Schmidt, F. L. \& Hunter, J. E. (1983). Individual differences in productivity: An empirical test of estimates derived from studies of selection procedure utility. Journal of Applied Psychology, 68, 407-415.

Schmitt, N. \& Chan, D. (1998). Personnel selection: A theoretical approach. Thousand Oaks, CA: Sage Publications.

Schneider, B., Goldstein, H.W. \& Smith, D.B. (1995). The ASA Framework: An Update. Personnel Psychology, 48, 747-779.

Schneider, B. (1987). The people make the place. Personnel Psychology, 40, 437-453

Schneier CE. (1977). Operational Utility and Psychometric Characteristics of Behavioral Expectation Scales: A cognitive Reinterpretation. Journal of Applied Psychology, 62, 541-548.

Sears, G. J. \& Rowe, P. M (2003). A personality-based similar-to-me effect in the employment interview: conscientiousness, affect-versus competence-mediated interpretations, and the role of job relevance. Canadian Journal of Behavioural Science, 35(1), 13-24.

Spengler, P. M., \& Strohmer, D. C. (1994). Clinical judgmental biases: The moderating roles of counselor cognitive complexity and counselor client preferences. Journal of Counseling Psychology, 41(1), 1-10.

Sternberg, R. J. (2000). The concept of intelligence. In R. J. Sternberg (Ed.), Handbook of intelligence (pp. 3-15). New York: Cambridge University Press.

Terpstra, D. \& Rozell, E. (1997). Why some potentially effective staffing practices are seldom used. Public Personnel Management, 26, 483-495.

Terpstra, D. E./Rozell, E. J. (1993): The relationship of staffing practices to organizational level measures of performance. Personnel Psychology, 46, 27-48.

Tuckman, B. W. (1964). Personality structure, group composition, and group functioning. Sociometry, 1964, 27(4), 469-487.

Tripodi, T., \& Bieri, J. (1963). Cognitive complexity as a function of own and provided constructs. Psychological Reports, 13, 26.

Wilk, S., \& Cappelli, P. (2003). Determinants and Outcomes of Employee Selection Procedures. Personnel Psychology, 56(1), 103-125.

Wofford, J. C. (1994). An examination of the cognitive processes used to handle employee job problems. Academy of Management Journal, 37(1), 180-192.

Zhao, H. \& Seibert, S. E. (2006). The Big Five personality dimensions and entrepreneurial status: A meta-analytical review. Journal of Applied Psychology, 91, 259-271. 


\section{APPENDICES}

\section{Appendix A}

\section{Instructions}

Please indicate whether the jobs presented are high or low in terms of safety concerns, complexity, and wages. Here are the definitions of these categories.

SAFETY CONCERN refers to whether or not a job involves the safety of others. A job which involves the safety of others is considered "high" in terms of safety concerns.

COMPLEXITY/TRAINING REQUIREMENT refers to how much training a job requires. A job with low training requirements is one requiring less than 1 year of training. On the other hand, if a job requiring more than 1 year of training is considered to have high complexity/training needs.

SALARY/WAGE refers to high versus low paying jobs (typical salary). A low salary job is one which pays less than $\$ 15 /$ hour or $\$ 31,500$ /year. A high salary job is one which pays more than $\$ 20 /$ hour or more than $\$ 40,000$ a year. 


\section{JOB DESCRIPTIONS}

Please indicate whether the jobs listed are high or low in terms of safety concerns, complexity, and wages.

SAFETY CONCERN - refers to whether or not a job involves the safety of others.

COMPLEXITY/TRAINING REQUIREMENTS - refers to how much training a job requires. Low (0-12 months) VS. High (12 or more months).

SALARY/WAGE - refers to high versus low paying jobs. Low (less than $\$ 15 /$ hour; Less than 31,500 year) VS High (more than $\$ 20 /$ hour; More than 40,000 year).

Probation Officer
Explosives Workers and Blasters
Carpet Installers
Tire Repairers and Changers
Crossing Guards
Taxi Driver
Animal Trainers
Advertising Sales Agents
Telecommunications Line Installers
Tax Preparer
Parking Lot Attendant
Jeweler
Air traffic controller
Insurance Adjusters and Examiners
School Bus Drivers
Subway/Train Operator
Pest Control Workers
Personal and Home Care Aides
Gas Plant Operators
Postal Service Mail Carriers




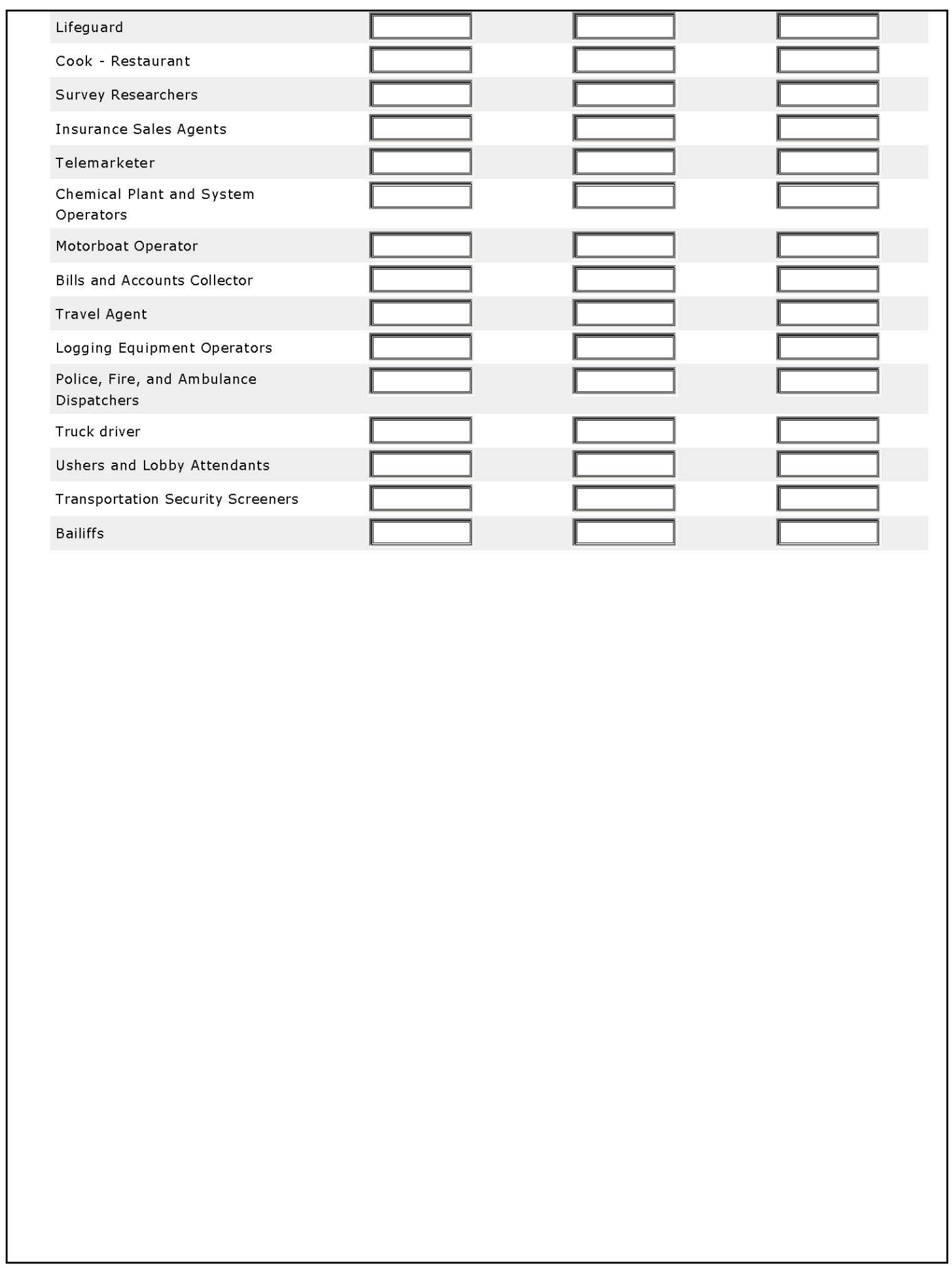


Appendix B

\begin{tabular}{|c|c|c|c|c|}
\hline Job & $\begin{array}{l}\text { Applicant } \\
\text { Pool }\end{array}$ & $\begin{array}{c}\text { Safety } \\
\text { Concerns }\end{array}$ & $\begin{array}{c}\text { Complexity/ } \\
\text { Training }\end{array}$ & $\begin{array}{c}\text { Salary/ } \\
\text { Wage }\end{array}$ \\
\hline Telemarketer & High & Low & Low & Low \\
\hline Air traffic controller & Low & High & High & High \\
\hline Tax Preparer & High & Low & High & High \\
\hline School Bus Drivers & Low & High & Low & Low \\
\hline Explosives Workers and Blasters & High & High & High & Low \\
\hline Insurance Adjusters and Examiners ${ }^{4}$ & Low & High & Low & High \\
\hline Jeweler & Low & Low & High & High \\
\hline Gas Plant Operators $^{3}$ & High & High & High & High \\
\hline Ushers and Lobby Attendants $^{1}$ & Low & Low & Low & Low \\
\hline Crossing Guards $^{2}$ & High & High & Low & Low \\
\hline Advertising Sales Agents & Low & Low & Low & High \\
\hline Truck driver $^{4}$ & Low & High & Low & High \\
\hline Chemical Plant and System Operators $^{3}$ & High & High & High & High \\
\hline Survey Researcher & Low & Low & High & Low \\
\hline Police, Fire, and Ambulance Dispatchers & High & High & Low & High \\
\hline Cook & High & Low & High & Low \\
\hline Insurance Sales Agents & High & Low & Low & High \\
\hline Subway Train Operator & Low & High & High & Low \\
\hline Carpet Installer $^{1}$ & Low & Low & Low & Low \\
\hline Tire Repairers $^{2}$ & High & High & Low & Low \\
\hline
\end{tabular}




\section{Appendix C}

\section{Job Recomendations - Instructions}

For this survey you are to assume the role of a "Personnel Recruiter".

You are part of a staffing company specializing in helping other organizations recruit workers to fill their open positions and meet staffing needs.

Your role is to recommend potential candidates to organizations for further evaluation, training and consideration for employment.

There is a selection process consisting of:

- A general skills test

- Interview

- Personality test

Every candidate goes through this process. The scores from the general skills test, interview and personality test are combined and converted into one score ranging from 0 to 100 . The passing score is 60 .

Eligible candidates scoring 60 and above are placed in one of 4 groups according to their score in the selection process:

- Group 1 - candidates with scores ranging from 60-70

- Group 2 - candidates with scores ranging from 71-80

- Group 3 - candidates with scores ranging from 81-90

- Group 4 - candidates with scores ranging from 91-100

You have already forwarded candidates from groups 2-4. Please consider candidates from Group 1 (6070) for each of the positions presented and indicate the likelihood of recommending a candidate from this group to the organization in need. 


\section{Job Recommendations}

\section{Instructions Recap}

The organizations need candidates for the positions being presented to you.

You will be presented with 20 jobs and will determine whether you would recommend a candidate from Group 1 (scores ranging from 60-70) to the organizations in need.

The positions presented will contain a general description of the job. Please review this information in making your decisions. 
Position: Telemarketer - Solicit orders for goods over the telephone.

\# of candidates needed: 14

\# of candidates already forwarded: 5

Salary: $\$ 9.75$ hourly; $\$ 20,280$ annual

Tasks:

- Deliver prepared sales talks describing products to persuade potential customers.

- Contact businesses by telephone to solicit sales for goods or services.

- Obtain customer information and enter orders into computers.

Job Training Needed: Low ( 0 to 3 months of training)

How likely are you to recommend a candidate from Group 1 for this job? very Unlikely $\bigcirc$ Unlikely $\underset{\substack{\text { Somewhat } \\ \text { Unlikely }}}{\substack{\text { Somewhat } \\ \text { Likely }}} \bigcirc$ Likely very Likely traffic between altitude sectors and control centers.

\# of candidates needed: 6

\# of candidates already forwarded: 5

Salary: $\$ 56.37$ hourly; $\$ 117,240$ annual

Tasks:

- Issue landing and take-off authorizations and instructions.

- Monitor the movement of aircraft to minimize delays and maximize safety.

- Provide flight path changes or directions to emergency landing fields.

Job Training Needed: High (12-24 months of training)

How likely are you to recommend a candidate from Group 1 for this job?

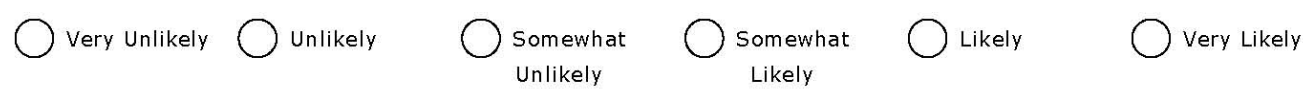


Position: Tax Preparer - Prepare tax returns but do not have the background or responsibilities of an accredited or certified public accountant.

\# of candidates needed: 14

\# of candidates already forwarded: 5

Salary: $\$ 22.15$ hourly; $\$ 46,072$ annual

Tasks:

- Compute taxes owed or overpaid, and complete entries on forms.

- Use all appropriate adjustments, deductions, and credits to keep clients' taxes to a minimum.

- Check data input or verify totals on forms prepared by others to detect errors.

Job Training Needed: High (12-24 months of training)

\section{How likely are you to recommend a candidate from Group 1 for this job?}

$\bigcirc$ very Unlikely $\bigcirc$ unlikely

Somewhat Unlikely

$\bigcirc$ somewhat

$\bigcirc$ Likely Likely

$\bigcirc$ very Likely 
Position: Explosives Workers and Blasters - Place and detonate explosives to demolish structures or to loosen, remove, or displace earth, rock, or other materials.

\# of candidates needed: 15

\# of candidates already forwarded: 5

Salary: $\$ 14$ hourly, $\$ 29,120$ annual

Tasks

- Examine blast areas to determine amounts and kinds of explosive charges needed.

- Place safety cones around blast areas to alert others and ensure blast sites are clear prior to explosions.

- Place explosive charges in holes or other spots; then detonate explosives to demolish structures.

Job Training Needed: High (12 months of training)

How likely are you to recommend a candidate from Group 1 for this job?

$\bigcirc$ very unlikely $\bigcirc$ unlikely

Somewhat Unlikely

Somewhat

Likely

Very Likely Likely

Position: Insurance Adjuster and Examiner - Investigate, analyze, and determine the extent of insurance company's liability concerning personal, casualty, or property loss.

\# of candidates needed: 6

\# of candidates already forwarded: 5

Salary: $\$ 24.36$ hourly; $\$ 50,660$ annual

Tasks:

- Interview with claimant and witnesses and inspect damage to determine liability.

- Negotiate claim settlements and recommend litigation when settlement cannot be negotiated.

- Examine claims forms to determine insurance coverage.

Job Training Needed: Low ( 6 months of training)

How likely are you to recommend a candidate from Group 1 for this job?
very unlikely
Unlikely
somewhat Unlikely
Somewhat Likely
Likely
$\bigcirc$ very Likely

$$
\text { Likely }
$$


Position: Jeweler - Fabricate and repair jewelry articles. Make models or molds to create jewelry items.

\# of candidates needed: 7

\# of candidates already forwarded: 5

Salary: $\$ 23$ hourly; $\$ 47,840$ annual

Tasks:

- Clean and polish metal items and jewelry pieces.

- Create jewelry from materials such as gold, silver, platinum, and precious or semiprecious stones.

- Make repairs, soldering pieces of jewelry together, and replacing broken mountings.

Job Training Needed: High (12 months of training)

\section{How likely are you to recommend a candidate from Group 1 for this job?}

$\bigcirc$ Very Unlikely Unlikely
Somewhat Unlikely $\bigcirc$ somewhat Likely
Cikely $\bigcirc$ Very Likely

Position: Gas Plant Operator - Distribute or process gas for utility companies by controlling compressors to maintain specified pressures on main pipelines.

\# of candidates needed: 14

\# of candidates already forwarded: 4

Salary: $\$ 25.80$ hourly; $\$ 53,670$ annual

Tasks:

- Monitor transportation and storage of flammable and other dangerous products.

- Monitor equipment functioning, observe temperature, level, and flow gauges, and perform regular unit checks.

- Determine causes of abnormal pressure variances, and make recommendations.

Job Training Needed: High ( 1 to 2 years of training)

How likely are you to recommend a candidate from Group 1 for this job?

$\bigcirc$ very Unlikely $\bigcirc$ unlikely

Somewhat Unlikely

Somewhat Likely

Likely

Very Likely Unlikely Likely 
Position: Ushers and Lobby Attendants - Assist patrons at entertainment events by collecting admission tickets and passes, assisting in finding seats, searching for lost articles, and locating such facilities as rest rooms and telephones.

\# of candidates needed: 7

\# of candidates already forwarded: 6

Salary: $\$ 7.64$ hourly, $\$ 15,880$ annual

Tasks

- Sell and collect admission tickets and passes from patrons at entertainment events.

- Maintain order and ensure adherence to safety rules.

- Assist patrons in finding seats, lighting the way with flashlights if necessary.

Job Training Needed: Low (0 to 3 months)

How likely are you to recommend a candidate from Group 1 for this job?

$\bigcirc$ very Unlikely $\bigcirc$ unlikely

Somewhat Unlikely
Somewhat Likely
Cikely

$\bigcirc$ Very Likely

Position: Crossing Guards- Guide or control vehicular or pedestrian traffic at such places as streets, schools, railroad crossings, or construction sites.

\# of candidates needed: 14

\# of candidates already forwarded: 4

Salary: $\$ 10.13$ hourly, $\$ 21,060$ annual

Tasks

- Monitor traffic flow to locate safe gaps through which pedestrians can cross streets.

- Direct or escort pedestrians across streets, stopping traffic as necessary.

- Direct traffic movement or warn of hazards, using signs, flags, lanterns, and hand signals.

Job Training Needed: Low ( 0 to 3 months of training)

How likely are you to recommend a candidate from Group 1 for this job?
very unlikely
Unlikely
Somewhat Unlikely
Somewhat Likely
Likely
$\bigcirc$ very Likely Likely 
Position: Advertising Sales Agents - Sell or solicit advertising, including graphic art, advertising space in publications, custom made signs, and TV/radio advertising time.

\# of candidates needed: 5

\# of candidates already forwarded: 4

Salary: $\$ 22.12$ hourly; $\$ 46,000$ annual

Tasks:

- Prepare and deliver sales presentations to customers to sell advertising programs.

- Process all correspondence and paperwork related to accounts.

- Provide clients with estimates of the costs of advertising products or services.

Job Training Needed: Low ( 3 to 6 months of training)

\section{How likely are you to recommend a candidate from Group 1 for this job?}

$\bigcirc$ very Unlikely $\bigcirc$ unlikely

Somewhat Unlikely

Somewhat

Likely

$\bigcirc$ very Likely Likely

loose, or packaged form.

\# of candidates needed: 6

\# of candidates already forwarded: 5

Salary: $\$ 25.00$ hourly; $\$ 52,000$ annual

Tasks:

- Check vehicles before driving them to ensure that mechanical, safety, and emergency equipment is in good working order.

- Obtain receipts or signatures when loads are delivered, and collect payment for services.

- Report vehicle defects, accidents, traffic violations, or damage to the vehicles.

Job Training Needed: Low ( 3 to 6 months of training)

\section{How likely are you to recommend a candidate from Group 1 for this job?}

$\bigcirc$ very unlikely $\bigcirc$ unlikely

Somewhat Unlikely

Somewhat Likely

Likely

$\bigcirc$ Very Likely Likely 
Position: Chemical Plant Operator - Control or operate an entire chemical process or system of machines.

\# of candidates needed: 14

\# of candidates already forwarded: 5

Salary: $\$ 26.00$ hourly; $\$ 54,080$ annual

Tasks:

- Move control settings to make necessary adjustments on equipment units.

- Regulate or shut down equipment during emergency situations.

- Confer with technical and supervisory personnel to report or resolve conditions affecting safety.

Job Training Needed: high (12 to 18 months of training)

\section{How likely are you to recommend a candidate from Group 1 for this job?}

$\bigcirc$ very Unlikely $\bigcirc$ unlikely

Somewhat

Unlikely Likely

somewhat

Likely

$\bigcirc$ very Likely

Position: Survey Researcher - Design and conduct surveys. Supervise interviewers who conduct the survey in person or over the telephone.

\# of candidates needed: 7

\# of candidates already forwarded: 6

Salary: $\$ 13.00$ hourly; $\$ 27,040$ annual

Tasks:

- Conduct research in order to gather information about survey topics.

- Prepare and present summaries and analyses of survey data.

- Consult with clients in order to identify survey needs and any specific requirements.

Job Training Needed: High (12 months of training)

How likely are you to recommend a candidate from Group 1 for this job?
very Unlikely
Unlikely
somewhat
somewhat
Likely Likely
$\bigcirc$ very Likely 
Position: Police Dispatchers - Receive complaints from public concerning crimes and police emergencies.

\# of candidates needed: 16

\# of candidates already forwarded: 5

Salary: $\$ 20.00$ hourly; $\$ 41,600$ annual

Tasks:

- Determine response requirements and relative priorities of situations, and dispatch units.

- Question callers to determine their locations, and the nature of their problems to determine type of response needed.

- Maintain access to, and security of, highly sensitive materials.

Job Training Needed: Low ( 6 months of training)

How likely are you to recommend a candidate from Group 1 for this job?
Very Unlikely
Unlikely
Somewhat Unlikely
Somewhat
Cikely
Very Likely Likely

Position: Cook - Prepare, season, and cook soups, meats, and vegetables. May order supplies, or plan menu.

\# of candidates needed: 15

\# of candidates already forwarded: 4

Salary: $\$ 9.78$ hourly; $\$ 20,324$ annual

Tasks:

- Season and cook food according to recipes or personal judgment.

- Portion, arrange, and garnish food, and serve food to waiters or patrons.

- Observe and test foods to determine if they have been cooked sufficiently, using methods such as tasting, smelling, or piercing them with utensils.

Job Training Needed: High (12 months training)

\section{How likely are you to recommend a candidate from Group 1 for this job?}

$\bigcirc$ very Unlikely $\bigcirc$ unlikel

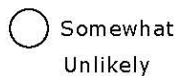

Somewhat Likely

Likely

$\bigcirc$ Very Likely Unlikely 
Position: Insurance Sales Agent - Sell life, property, casualty, health, automotive, or other types of insurance.

\# of candidates needed: 14

\# of candidates already forwarded: 5

Salary: $\$ 22.50$ hourly; $\$ 46,800$ annual

Tasks:

- Call on policyholders to deliver and explain policy.

- Seek out new clients and develop clientele by networking to find new customers.

- Calculate premiums and establish payment method.

Job Training Needed: Low (6 to 9 months of training)

\title{
How likely are you to recommend a candidate from Group 1 for this job?
}

$\bigcirc$ very Unlikely $\bigcirc$ unlikely

Somewhat Unlikely

Somewhat

Likely Likely

Very Likely

\begin{abstract}
(1)
\end{abstract}

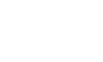

powered streetcar to transport passengers.

\# of candidates needed : 6

\# of candidates already forwarded: 5

Salary: $\$ 14.00$ hourly; $\$ 29,120$ annual

Tasks:

- Operate controls to open and close transit vehicle doors.

- Direct emergency evacuation procedures.

- Drive and control rail-guided public transportation, such as subways, elevated trains, trams, or trolleys, in order to transport passengers.

Job Training Needed: High (12 months of training)

How likely are you to recommend a candidate from Group 1 for this job?
$\bigcirc$ very Unlikely $\bigcirc$ unlikely Somewhat
Unlikely
Somewhat
Likely
$\bigcirc$ Very Likely Likely 
Position: Carpet Installer - Lay and install carpet from rolls or blocks on floors. Install padding and trim flooring materials.

\# of candidates needed : 5

\# of candidates already forwarded: 4

Salary: $\$ 12.00$ hourly; $\$ 24,960$ annual

Tasks:

- Join edges of carpet and seam edges where necessary.

- Take measurements and study floor sketches to calculate the area to be carpeted.

- Install carpet on some floors using adhesive, following prescribed method.

Job Training Needed: Low ( 0 to 3 months of training)

\section{How likely are you to recommend a candidate from Group 1 for this job?}

$\bigcirc$ Very Unlikely Unlikely
Somewhat Unlikely somewhat Likely
Likely

$\bigcirc$ Very Likely

\section{.}




\title{
Appendix D
}

\section{$\mathrm{CC}$}

INSTRUCTIONS: This part of the survey asks you to rate 4 individuals of your choice on 6 separate word pairings. Your ratings will be completely confidential. Please follow the steps outlined below.

Step 1: Enter the initials for 4 different individuals that correspond to the roles presented in the table below. Full names are NOT necessary, as you are the only one that needs to know whom corresponds to the specified relationships presented.

Step 2: Starting with the first word pairing (outgoing-shy), rate each person using the scale provided. Scale points range from $3 \mathrm{~L}$ to $3 R$ for each word pairing. Simply select your ratings (e.g., $3 \mathrm{~L}, 2 \mathrm{~L}, 1 \mathrm{~L}, 1 \mathrm{R}$, $2 R$, and $3 R$ ) for the word pairing from the drop down menu.

Step 3: Continue to the next word pairing (adjusted-maladjusted) and rate each person again. Continue this process (one row at a time) until all persons are rated on all word pairings.

\section{Enter the initials for $\mathbf{4}$ different individuals that correspond to the roles} presented.

\author{
Mother \\ Friend of Opposite Gender \\ Person with whom you feel most uncomfortable \\ Supervisor or boss
}

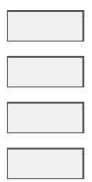

Starting with the first word pairing (outgoing-shy), rate each person using the continuum provided.

For example if you feel the person you are describing is very outgoing then you may choose a rating of $1 \mathrm{~L}$. On the other hand, if a person is somewhat shy, you would choose a rating of $2 R$.

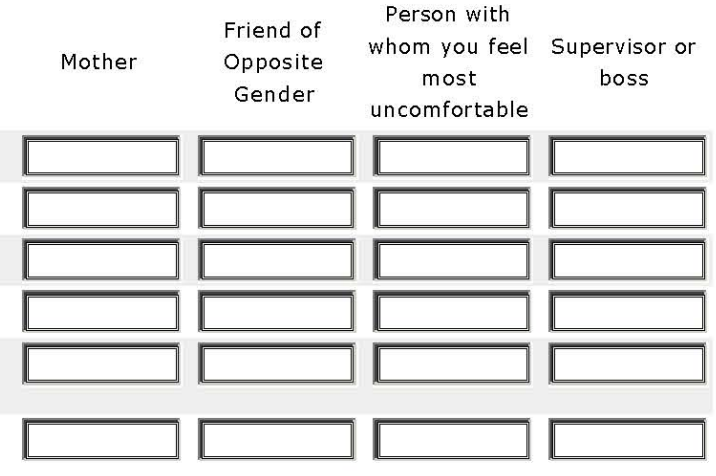

Outgoing - 3L 2L 1L 1R 2R 3R - Shy

Adjusted - 3L 2L 1L 1R 2R 3R - Maladjusted

Decisive - $3 L 2 L 1 L 1 R 2 R 3 R$ - Indecisive

Calm - 3L 2L 1L 1R 2R 3R - Excitable

Interested in others - $3 L 2 L 1 L 1 R \quad 2 R 3 R$ - Selfabsorbed

Cheerful - 3L 2L 1L 1R 2R 3R - Ill-humored 
Appendix E

\section{Personality - Instructions}

In this first section, there are phrases describing behaviors. Please use the rating scale provided to describe how accurately each statement describes you.

Describe yourself as you generally are now, not as you wish to be in the future. Describe yourself as you honestly see yourself, in relation to other people you know of the same sex as you are, and roughly your same age.

So that you can describe yourself in an honest manner, your responses will be kept in absolute confidence.

Please read each statement carefully.

Then, choose the appropriate response from 1 to 5 to describe how accurately each statement describes you.

How accurately does each statement describe you?

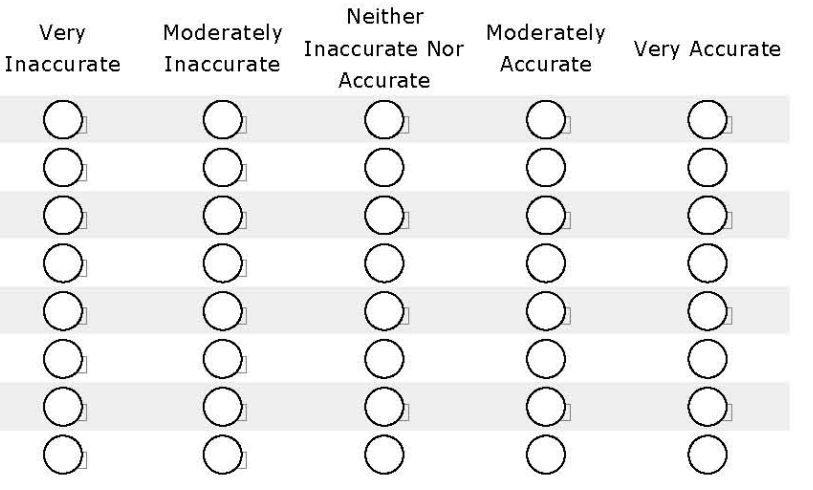


Please read each statement carefully.

Then, choose the appropriate response from 1 to 5 to describe how accurately each statement describes you.

How accurately does each statement describe you?

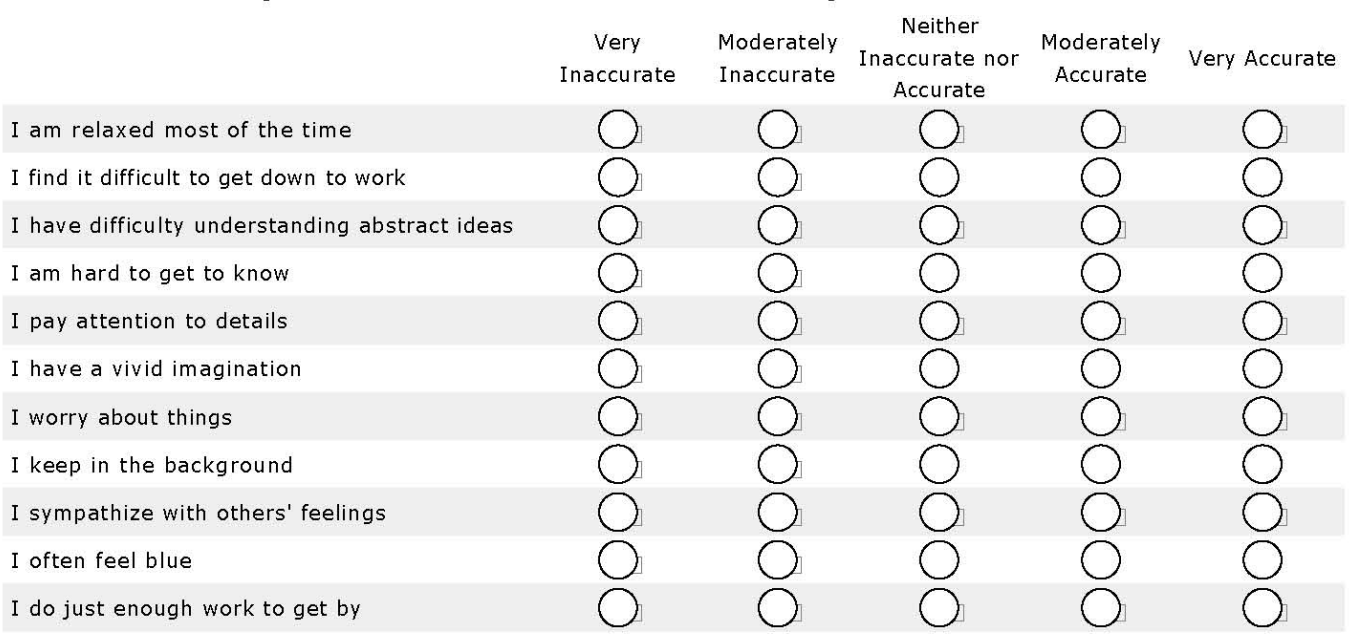

How accurately does each statement describe you?

I am not interested in abstract ideas
I am not easily bothered by things
I get chores done right away
I start conversations
I knjoy thinking about things how to comfort others
I have little to say
I need a push to get started
I make plans and stick to them




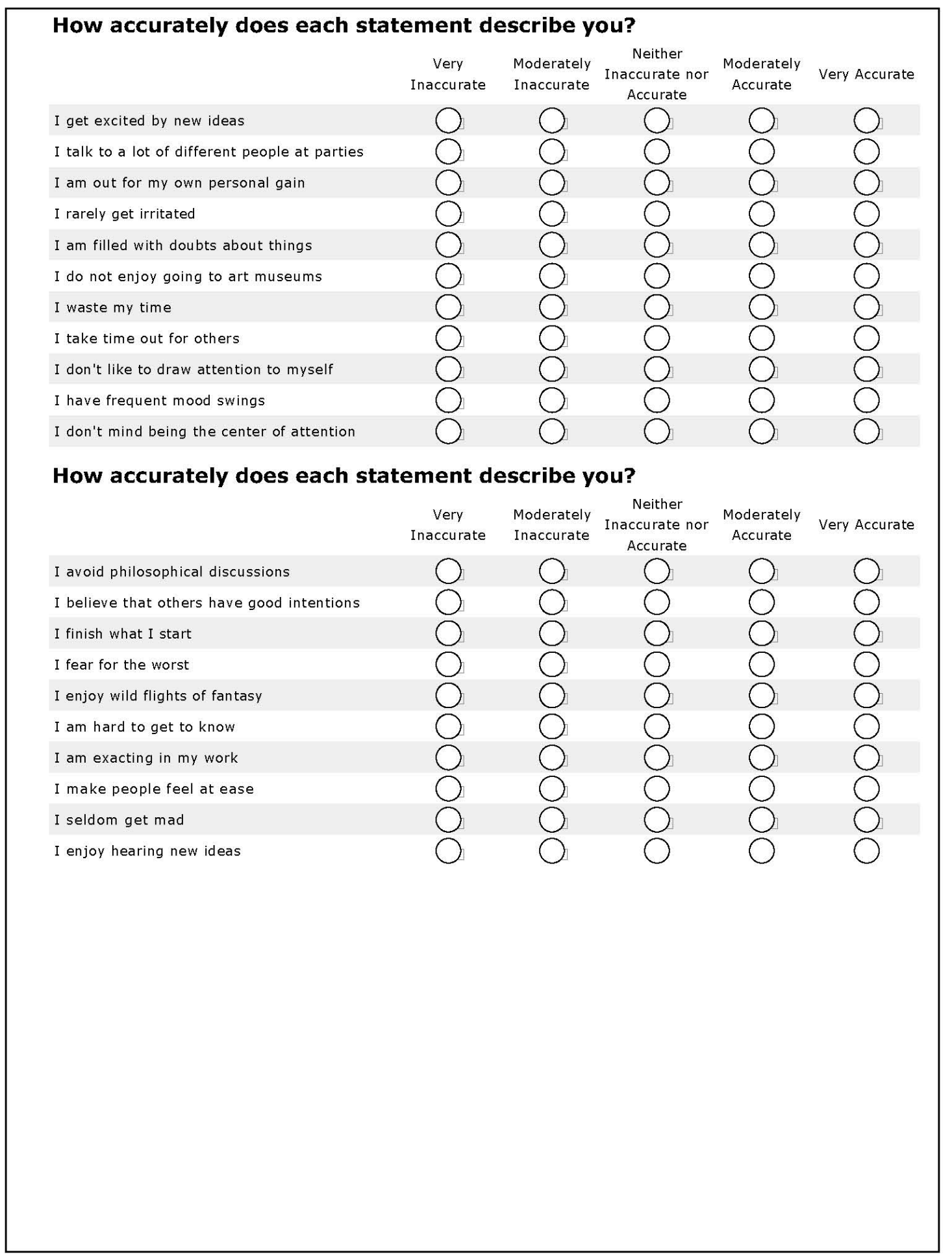


Appendix F

\section{Demographic}

\section{Race/Ethnicity}

Asian or Oriental

OHispanic White

Hispanic African American

$\bigcirc$ Non-Hispanic White

African American

other

\section{Gender}

Male

Pemale

\section{Please indicate your age:}

\section{Student status}

Part-time

Full-time

Not a Student 


\section{Job Status}

$\bigcirc$ Employed part-time

Employed full-time

Not currently employed

Current GPA (if you gradudated, what was your graduating gpa):

highest level of education you have completed:

High school diploma

1 year of undergraduate

2 years of undergraduate (AA)

(3 years of undergraduate

(4 years of undergraduate (Bachelors)

$\bigcirc$ Graduate student

Masters degree

$\bigcirc$ Doctorate degree

Have you ever been through a job interview?

Yres

No

If yes, how many total times approximately have you been interviewed? (If you have never been interviewed for a job just indicate 0 ) 
Have you ever been involved in the selection process of recruiting, interviewing and/or selecting candidates

Ores
No

How often have you been invovled in a selection process:

I have never been invovled in a selection process

Rarely ( $1-3$ times)

Often (3-10 times)

very Often $(10+$ times)

Ongoing part of my job

Have you ever been in a serious accident at your workplace?

Yres

No

Did you have to see a doctor/go to a hospital as a result of this accident?

$\bigcirc$ Never had an accident at work

Had an accident but did not go to doctor/hospital

Went to hospital

went to the doctor

Have you ever witnessed a serious accident of any kind at your workplace?

Ores

No

Have you ever had a job in a work environment you percieved to be dangerous?

Yes

$\bigcirc$ No 
Appendix G

Manipulation Check

\section{Check}

1. Which characteristic was NOT a part of the job descriptions presented:

$\bigcirc$ salary

Training needed

$\bigcirc$ Minimum Education Required

$\bigcirc$ Number of Applicants

2. Which of the following statements is true for the candidate group being considered for employment?

The candidates being recommended were part of the group with the highest scores in the selection process (90100).

The candidates being recommended were part of the group with the lowest passing scores in the selection process $(60-70)$

The candidates being recommended were from all of the groups and their scores ranged from $60-100$ in the selection process.

The candidates being recommended all received failing scores in the selection process.

3. Please indicate whether the jobs listed are high or low in terms of safety concerns, complexity, and wages.

SAFETY CONCERN - refers to whether or not a job involves the safety of others.

COMPLEXITY/TRAINING REQUIREMENTS - refers to how much training a job requires. Low (0-12 months) VS. High (12 or more months).

SALARY/WAGE - refers to high versus low paying jobs. Low (less than $\$ 15 /$ hour; Less than 31,500 year) VS High (more than $\$ 20 /$ hour; More than 40,000 year).

Telemarketer
Air traffic controller
Tax preparer
Crossing Guards




\section{JULIO FERNANDEZ DE CUETO}

1998

1998-1999

2003

2003-2005

2005-2011

2006-2010

2010-Present
B.A., Psychology (Summa Cum Laude)

Florida International University

Coventry Healthcare - JMH

Intake Coordinator

M.S., I/O Psychology

Florida International University

Florida State University - Physical Challenge \& Health Study Field Researcher

Private Consulting

Miami Dade College

Assessment Center - Program Manager

Miami Dade College

Director of Testing

\section{PUBLICATIONS AND PRESENTATIONS}

Fernández de Cueto, J. E. \& Sánchez J. I. (2011). Context-specific versus broad predictors in International Assignments. Revista de Psicologia del Trabajo y de las Organizaciones, 27 (1): 5-15.

Fernández de Cueto, J. \& Sánchez J. (2004, April) Validity of Context-specific Versus Broad Characteristics in International Assignments. Poster accepted for presentation at the annual meeting of the Society of Industrial and Organizational Psychologists (SIOP). Chicago, IL.

Panzer, F., Fernández de Cueto, J., DeChurch, L., Alonso, A., Marks, M., Reichard, R., \& Sims, D. (2003, April). Diversity in Actions Teams. Poster presented at the annual meeting of the Society of Industrial and Organizational Psychologists (SIOP). Orlando, FL.

Alonso, A., Viswesvaran, V., Sánchez, J., Spector, P., \& Fernández de Cueto, J. (2003, April). The Role of Locus of Control on Test-Retest Reliability Estimates. Poster presented at the annual meeting of the Society of Industrial and Organizational Psychologists (SIOP). Orlando, FL. 